\title{
Production and on-line comprehension of definite articles and clitic pronouns by Greek sequential bilingual children and monolingual children with specific language impairment
}

\author{
VASILIKI CHONDROGIANNI \\ Bangor University \\ THEODOROS MARINIS and SUSAN EDWARDS \\ University of Reading \\ ELMA BLOM \\ University of Utrecht
}

Received: April 13, 2013 Accepted for publication: December 24, 2013

ADDRESS FOR CORRESPONDENCE

Vasiliki Chondrogianni, School of Linguistics and English Language, Bangor University, Bangor LL57 2DG, UK. E-mail: v.chondrogianni@bangor.ac.uk

\begin{abstract}
The present study compared production and on-line comprehension of definite articles and third person direct object clitic pronouns in Greek-speaking typically developing, sequential bilingual (L2-TD) children and monolingual children with specific language impairment (L1-SLI). Twenty Turkish Greek L2-TD children, 16 Greek L1-SLI children, and 31 L1-TD Greek children participated in a production task examining definite articles and clitic pronouns and, in an on-line comprehension task, involving grammatical sentences with definite articles and clitics and sentences with grammatical violations induced by omitted articles and clitics. The results showed that the L2-TD children were sensitive to the grammatical violations despite low production. In contrast, the children with SLI were not sensitive to clitic omission in the on-line task, despite high production. These results support a dissociation between production and on-line comprehension in L2 children and for impaired grammatical representations and lack of automaticity in children with SLI. They also suggest that on-line comprehension tasks may complement production tasks by differentiating between the language profiles of L2-TD children and children with SLI.
\end{abstract}

Monolingual children with specific language impairment (L1-SLI) and typically developing sequential bilingual (L2-TD) children have been shown to have

(C) Cambridge University Press 2014 0142-7164/14 \$15.00 
language-specific problems with morphosyntactic properties, such as tense morphemes in English (Paradis, Rice, Crago, \& Marquis, 2008) and definite articles and clitic pronouns in Romance languages (Bottari, Cipriani, Chilosi, \& Pfanner, 1998; Jakubowicz, Nash, Rigaut, \& Gerard, 1998). Most studies have focused primarily on production data and have reported a similar acquisition profile in the two populations (Håkansson \& Nettelbladt, 1996; Paradis, 2005; Paradis \& Crago, 2000).

However, a number of recent studies investigating the acquisition of morphosyntactic phenomena in L2-TD children using off-line (Grüter \& Crago, 2012; Marinis \& Chondrogianni, 2011) and on-line comprehension tasks (Blom \& Vasić, 2011; Chondrogianni \& Marinis, 2012; Vasić \& Blom, 2011) have reported that their pattern differs from that of children with SLI (Marinis \& Saddy, 2013; Montgomery \& Leonard, 1998, 2006). Yet, the studies directly comparing both groups on expressive and receptive abilities remain few (e.g., Grüter, 2005; Paradis et al., 2008).

The investigation of the different modalities aims at unravelling the nature of the production problems of the L2-TD children and the children with SLI in relation to the status of their underlying grammatical representations. It further aims at exploring whether more sensitive experimental methods that measure language comprehension in real time, such as on-line processing tasks, can help us identify similarities and differences between the two populations and disentangle the processes that subserve typical bilingual from impaired monolingual development (Marinis, 2010).

The present study addresses these issues by directly comparing the performance of L1 Greek-speaking children with SLI with Greek-speaking L2-TD children with L1 Turkish on production and on-line comprehension tasks examining definite articles and clitic pronouns. We investigated whether L2-TD children pattern similarly to children with SLI on production. We further examined whether children with SLI and L2-TD children exhibited sensitivity to the grammatical violations induced by article and clitic omission in an on-line processing task, and we explored whether on-line processing tasks can complement production tasks in differentiating between the language profiles of L2-TD children and children with SLI.

\section{GREEK DEFINITE ARTICLES AND CLITIC PRONOUNS}

Greek is a language with a relatively free word order and rich morphology, which allows for the omission of pronominal subjects (subject pro-drop language). Definite articles in Greek precede the noun and are used obligatorily with singular and

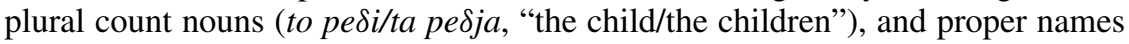
in argument positions, as in Example (1).

$\begin{array}{ll}\text { (1) I } \mathrm{a} a \mathrm{ti} & \text { Maria. } \\ \text { Saw.1SG the.DEF-ART } & \text { Maria } \\ \text { "I saw Mary" } & \end{array}$

Bare nouns are disallowed in the subject position; licit bare nouns can be licensed under certain circumstances, such as when they are in the object 
position and governed by a verb (Marinis, 2003; Sioupi, 2002), as in Example (2).

(2) Extise spiti sta Kiөira.

Build.3SG house on the Kithira.

"He built a house on Kithira"

The pronominal system of Greek has a bipartite distinction between strong and clitic pronouns. Strong pronouns can appear in the subject or the object position and can be placed postverbally, or preverbally, when focused or stressed ( $3 a-c)$. Greek has object clitics but no subject clitics. Object clitics always precede the finite verb and cannot be focused or stressed, as in Example (3d-f).

(3) a. i $\delta$ a afton

b. ??afton i $\delta$ a

c. AFTON i $\delta$ a

d. *iסa ton / TON

e. ton i $\delta$ a

f. *TON i $\delta$ a

"I saw him"

Definite articles and clitic pronouns are morphophonologically similar and are marked for phi features, namely gender and number, as well as case; clitic pronouns are also marked for person. Definite articles and clitic pronouns are weak monosyllabic unstressed forms that cliticise on their host, that is, definite articles cliticise on the noun and clitic pronouns on the verb.

Definite articles and clitic pronouns can have a fully referential use as in Examples (1) and (3), but they can also have a purely grammatical function, as in the case of definite articles' being used with proper names, or clitic pronouns referring to a sentential complement, as in Example (4) (Tsimpli \& Stavrakaki, 1999).

(4) To perimena oti $\theta$ a perasi tis eksetasis

It.CLIT expected that will pass the exams

"I expected him to pass the exams"

The purely grammatical function of definite articles and clitic pronouns coupled with their morphophonological similarity has led to the proposal that the two elements belong to the same determiner (D) category in Greek (Anagnostopoulou, 1999; Tsimpli \& Stavrakaki 1999). When used with proper names or in contexts such as in Example (4), they take on an expletive (resumptive) use; they serve as a mere spell-out of uninterpretable features (gender and number) and case, and they are not associated with semantic features of definiteness or referentiality (Tsimpli \& Stavrakaki 1999).

However, there are also some important differences between definite articles and clitic pronouns. Clitic pronouns constitute verbal arguments that are optionally produced under specific discourse conditions, and they have a more complex derivation than definite articles (Anagnostopoulou, 2003; Mavrogiorgos, 2010). 
More specifically, Mavrogiorgos (2010) argues that clitics are morphophonologically deficient elements with an impoverished structure. This impoverished structure gives rise to a hybrid status with clitics being both XP/X categories (for arguments whether they constitute DP/D or $\varphi \mathrm{P} / \varphi$, that is, mere spell-out of phi features, see Mavrogiorgos, 2010). In order for clitics to be assigned case and to check their phi features, they have to move to their verbal host. This movement takes place in an incorporation fashion, where clitics move as (argumental) phrases (XPs), but land as heads (Xs), that is, they get stripped off during the derivation. This is in contrast to definite articles that are base generated as heads of the determiner phrase (DP) and therefore involve no movement. Instead, cliticize only phonologically on the noun (Arvaniti, 1991). Differences in complexity between definite articles and clitic pronouns are important for their acquisition and will be addressed in the present study.

In the present study, the L2 children had Turkish as their L1. Turkish is a head-final language with agglutinative morphology and an unmarked subjectobject-verb word order. Turkish has no definite articles; the formal features of case and number are marked as nominal suffixes. Licit bare nouns in Turkish can be found in argument positions, as in Example (5) (Ketrez, 2005).

(5) Ayşe kitap / kitab- i okudu

Ayşe book/book.ACC read.3SG

"Ayşe read a book(s) / the book"

Case marking in Turkish interacts with the definiteness and referentiality of the noun. More specifically, direct objects bearing accusative case marking are interpreted as definite, whereas bare (noncase-marked) nouns are interpreted as nonreferential (Enç, 1991; Ketrez, 2005), as in Example (5).

In terms of the Turkish pronominal system, Turkish allows null objects in contexts where a referent has already been introduced into the discourse, as in Example (6) (Kornfilt, 1997).

(6) pro Buldum!
pro(object) found
"I found (them)"

In Example (6), the null pronoun replaces a previously introduced entity, for example, the keys. In the same context, Greek would license a direct object clitic pronoun.

In languages that do not grammaticalize definiteness via the use of overt definite articles, there is a controversy about whether they project a DP layer (Bošković, 2008; Öztürk, 2005). In these languages, accusative case is the most suitable candidate for heading the DP (Ketrez, 2005). Ketrez proposes that Turkish has a maximal category DP that closes off the noun phrase (NP) with accusative case heading the DP. More specifically, whenever the noun is case marked, it becomes referential and bears the [+definite] feature, and a DP projection can be postulated (Ketrez, 2005). In these contexts, case marking can serve as a type shifter in the same sense that an overt article has a type-shifting operation in 
languages that license overt articles (cf. Longobardi, 1994; Öztürk, 2005). In this account, nonovertly case-marked nouns are analyzed as NPs, which incorporate with their verbal host, while case-marked noun phrases constitute fully referential noun phrases (DPs).

For the purposes of the present study, we assume that both Greek and Turkish project a DP, with the cross-linguistic difference that this DP is headed by definite articles in Greek, whereas in Turkish it is headed by accusative case.

\section{Acquisition of Greek articles and clitic pronouns by L1-TD children and L1 children with SLI}

Longitudinal studies with L1-TD Greek children have shown that definite articles emerge very early, at around the age of 1 year, 9 months $(1 ; 9)$, and they are felicitously produced in more than $90 \%$ of obligatory contexts at around the age of 2;5 to 2;9 (Marinis, 2003). Furthermore, definite article production is higher in the subject than in the object position (Marinis, 2003). Longitudinal and experimental studies have shown that clitic pronouns appear in Greek between the ages of 1;7 and 2;1 (Marinis, 2000; Tsimpli, 2005) and are systematically produced to a ceiling rate by the age of 2;6 (Tsakali \& Wexler, 2003).

Despite the early acquisition of definite articles and clitic pronouns by Greek L1-TD children, there is evidence that definite articles and clitic pronouns show a high rate of omission, especially in preschool children with SLI (Diamanti, 2000; Mastropavlou, 2006; Tsimpli \& Mastropavlou, 2008; Tsimpli \& Stavrakaki, 1999; but cf. Manika, Varlokosta, \& Wexler, 2011; and Varlokosta, 2002, who report low omission of clitics in Greek children with SLI).

In a study with school-aged children with SLI with a mean age of 7;3, Stavrakaki (2001) reported that they had mastered the acquisition of definite articles and clitics, suggesting that children with SLI overcome with age previous problems with the two D-elements. Tsimpli and Mastropavlou (2008) compared a group of children ages $4 ; 0$ to $4 ; 6$ to a group of children ages $5 ; 6$ to $6 ; 2$ with SLI using naturalistic data. The younger group, which had received less treatment than the older group, had a higher rate of definite article omission (range $=38 \%-72 \%$ ) and clitic pronoun omission (23\%-68\%) than the older group, which had a much lower rate of definite article (5\%-7\%) and clitic pronoun omission (4\%-15\%). These studies indicate that the acquisition of definite articles and clitics is subject to age and treatment, although it was not possible to tease these two factors apart in the studies above.

To date, there is only one study examining off-line comprehension of strong and clitic pronouns in children with SLI by Stavrakaki and van der Lely (2010). They examined the production and comprehension of strong and clitic pronouns in different syntactic contexts in a group of nine older Greek children with SLI (mean age $=10 ; 6$, range $=7 ; 7-13 ; 5$ ) and three groups of TD younger, vocabularyand grammar-matched children. The results showed that the Greek children with SLI performed worse on third person direct object clitics compared with all the other pronominal constructions. They also performed slightly better on production (accuracy of $65 \%$ ) than on comprehension (accuracy of $\sim 55 \%$ or 4.4 out of 8 items) 
Chondrogianni et al.: Production and processing in L2 and SLI children

but significantly worse than all groups of TD younger children on both tasks. It is unclear whether this small difference between comprehension and production is meaningful. The authors regarded this as a task effect, and they attributed it to the metalinguistic demands of the comprehension (a four-picture selection task) compared with the cognitively less demanding production task. ${ }^{1}$

Finally, some studies have shown that clitic pronouns are more vulnerable than definite articles in children with SLI (Smith, 2008; Tsimpli, 2001). In an experimental study, Smith (2008) reported higher production rates of definite articles $($ mean $=88 \%)$ than clitics $($ mean $=64 \%)$ in a group of nine age $4 ; 9$ to $6 ; 8$ children with SLI. The children with SLI differed from their language-matched controls only in terms of clitic use but not in terms of article use, suggesting that clitics are more vulnerable than definite articles in children with SLI.

\section{Domain-general versus domain-specific accounts of SLI}

The acquisition and processing of definite articles and clitic pronouns provides a good testing ground for domain-specific and domain-general accounts of SLI due to the grammatical and phonetic properties of the two D-elements. Domainspecific accounts of SLI attribute the children's difficulties with definite articles and clitic pronouns to the grammatical properties of the two D-elements (Tsimpli \& Stavrakaki, 1999) and to the syntactic operations involved in the derivation of clitics (Stavrakaki \& van der Lely, 2010), whereas domain-general accounts focus on the phonetic properties of these grammatical morphemes (e.g., Leonard, 1989). We now discuss these different approaches in greater detail.

The interpretability hypothesis (IH; Tsimpli, 2001) assumes that children with SLI have a deficit specific to the domain of grammar that affects uninterpretable features (Chomsky, 1995). These are purely morphosyntactic features (case, gender, lack of referentiality), which carry no semantic content and may be associated with D-elements in Greek. These features will remain inaccessible for children with SLI. In the case of Greek children with SLI, Tsimpli and Mastropavlou (2008) argue that the delay observed in the acquisition of articles and clitic pronouns may be the result of (a) a genetically based reduced ability to analyze syntactically the L1 input or (b) the result of a deficit in the syntactic system which requires considerably more exposure to the input in order to achieve targetlike performance indirectly, that is, via a learning rather than an acquisition process. The latter claim derives from Paradis and Gopnik's (1997) implicit rule deficit account, which assumes that children with SLI are unable to form automatic and implicit rules based on grammatical features. In this account, children with SLI can compensate for grammatical deficits by resorting to explicitly learned metalinguistic rules. At the same time, length of treatment along with age may impact on their ability to employ explicit morphosyntactic rules (Paradis \& Gopnik, 1997; Ullman \& Gopnik, 1999).

Stavrakaki and van der Lely (2010) explain the late acquisition of Greek clitic pronouns in children with SLI within the computational grammatical complexity hypothesis (CGCH; Van der Lely \& Battell, 2003), which is a domain-specific account. According to the $\mathrm{CGCH}$, syntactic dependencies involving movement and chain formation between the moved constituent and its trace are impaired in 
children with SLI, and this impairment should lead to optionality in performance. Object clitics are interpreted through syntactic dependencies at the clausal level and require feature checking, movement, and chain formation. Therefore, they are expected to be impaired in children with SLI. Stavrakaki and van der Lely argue that the $\mathrm{CGCH}$ account captures the optionality demonstrated by the Greek children with SLI in their study. However, on a theoretical level and given the assumptions of this account, it is not clear why impairment in movement in children with SLI should lead to optionality and not to complete omission or lack of comprehension of the impaired structure.

Domain-general accounts attribute the difficulties of children with SLI to their well-documented processing limitations (Bishop, Carlyon, Deeks, \& Bishop, 1999; Montgomery \& Leonard, 1998). According to the surface account (Leonard, 1989, 2009; Leonard, Eyer, Bedore, \& Grela, 1997), grammatical morphemes with relatively short duration and low phonetic salience (e.g., single consonants or unstressed syllables) will be problematic for children with SLI. This account assumes that the morphosyntactic functions carried by the grammatical morphemes combined with their brevity will result in incomplete processing of these morphemes in children with SLI because of processing limitations. This will lead to underspecified morphological paradigms and hence may hinder the lexical representations of inflectional suffixes, which may lead to underspecified morphological paradigms (Paradis, 2010b). In this account, a minimal threshold of exposure is required before productive use of morphemes can be reached.

In the present study we explored these theoretical accounts by examining production and processing of morphosyntactic elements of low phonetic salience that carry uninterpretable features $(\mathrm{IH})$ and involve different syntactic operations $(\mathrm{CGCH})$.

\section{The acquisition of articles and clitics in Greek L2-TD children}

Greek-speaking L2-TD children with L1 Turkish have been shown to have problems acquiring definite articles and clitic pronouns in Greek (Chondrogianni, 2008a, 2008b; Tsimpli \& Mastropavlou, 2008). However, the studies differ with respect to the success rate that they report on articles and clitics for the L2-TD children.

In a small-scale study, Tsimpli and Mastropavlou (2008) examined the production of clitic pronouns and definite articles in the spontaneous speech of five 8to 9-year-old and five 11- to 12-year-old Turkish-speaking children with Greek as an L2. The results showed that both groups of L2-TD children omitted definite articles and clitic pronouns and that performance was better on definite articles compared with clitic pronouns. However, the older group of L2-TD children did not reach high accuracy on clitics (younger group: definite article: $62 \%$, clitics: $27 \%$; older group: definite article: $89 \%$, clitics: $56 \%){ }^{2}$

Chondrogianni (2008a, 2008b) examined the acquisition of definite articles and clitics in a cross-sectional study with 70 TD Turkish-speaking children with Greek as an L2 belonging to different proficiency levels (beginners to advanced) and aged between $7 ; 0$ and 12;0. Their mean age of L2 onset was 5;3 and their length of exposure ranged between 12 and 72 months. Definite articles and clitics were 
Chondrogianni et al.: Production and processing in L2 and SLI children

examined in referential anaphoric contexts using a narrative task. Clitics were also elicited using a picture-based production task following Schaeffer (2000), similar to the task in the present study.

The results showed that the low proficiency group with an average exposure to the L2 of less than 3 years (mean $=35$ months, range $=12-60$ months) had low production of definite articles (mean $=26.9 \%$ ). However, article production followed a steep developmental path that reached ceiling at intermediate $(86 \%)$ and advanced (95\%) proficiency levels. Few clitics were initially produced in the elicited production task $($ mean $=10.7 \%$, range $=0 \%-57.1 \%, S D=19.3$ ) and the developmental path of clitics was also more protracted than that of articles. L2-TD children were also able to produce a high rate of clitics at the advanced proficiency levels (narrative task $=96.8 \%$, elicited production task $=83 \%$ ). ${ }^{3}$ Omissions were the predominant error type for both article and clitic contexts, followed by substitutions (substitution errors were indefinite articles instead of definite articles, or full NPs instead of clitics).

The difficulties of the Greek-speaking L2-TD children with clitics and pronouns have been interpreted by Tsimpli and Mastropavlou (2008) within the IH (Tsimpli, 2003). More specifically, Tsimpli (2003) assumes that uninterpretable L2 features not present in the L1 are problematic for L2 learners and are susceptible to critical period effects. In the case of child L2 learners who are still within the critical period for language acquisition, uninterpretable features can be analyzed and integrated in the L2 grammar eventually but not following the same route as in the case of L1 acquisition. Targetlike acquisition is not guaranteed even at advanced stages of development. In the context of the acquisition of Greek articles and clitics by Turkish-speaking children with Greek as an L2, Tsimpli and Mastropavlou (2008) argue that the nature of the problem lies in that the L2 children misanalyze case in Greek as a lexical instead of a functional feature, because case in Turkish is a feature associated with nouns (lexical category), and in their analysis arguments are not DPs but case phrases or NPs. Consequently, L2 learners have problems analyzing definite articles and clitics as D-categories, which are linked with argument licensing in Greek. It is this parametric property associated with the representation of case as a feature on a lexical $(\mathrm{N})$ rather than a functional feature associated with argumenthood that is not reset in the L2 learners.

However, Tsimpli and Mastropavlou's (2008) analysis of case in Turkish is based on Kowaluk's (2001) analysis of Slavic languages and contrasts with other theoretical accounts that analyze case in Turkish as a potential head of the Dcategory. In these analyses, case can act as a nominal type shifter, since accusative case-marked nouns in Turkish become definite and resist incorporation with the verbal host (Öztürk, 2005). If the latter account is adopted, then a D-category can be postulated for both Greek and Turkish. However, this category is occupied by different morphophonological exponents in the two languages, namely, by definite articles in Greek and case in Turkish. When the DPs are referential in both languages, then they share interpretable features related to referentiality and should be learnable, especially by L2-TD children. ${ }^{4}$

Chondrogianni $(2008 \mathrm{a}, 2008 \mathrm{~b})$ postulated that nouns in Turkish and in Greek are DPs when case-marked or preceded by a definite article in referential 
contexts. The difficulties with articles and clitic pronouns in L2-TD children and the asymmetrical pattern in the acquisition of the two D-elements were attributed to two main factors. First, the low accuracy on articles and clitics may be attributed to the L2-TD children's difficulties with reassembling the L1 features into target morphophonological exponents in the L 2 in the form of definite articles and clitics (Lardiere, 2005), since these two morphophonological exponents of the D-category are missing in Turkish. ${ }^{5}$ Second, better performance on articles compared to clitics may be attributed to the derivational complexity of clitic pronouns, which move as heads and incorporate into their verbal host to check their case and phi features (Mavrogiorgos, 2010); articles do not show this derivational complexity. Chondrogianni (2008), following Lardiere's feature reassembly account (2005), argued that the morphosyntactic realization of a specific category in the L1 and the L2 may affect the L2 acquisition pattern. In the case of Turkish and Greek, both definite articles and case can head the D-category. However, its morphophonological manifestation in the two languages differs. In Greek, determiner is occupied by articles whereas in Turkish by case. The task of the Turkish L2 learner of Greek is to figure out that nouns in Greek turn into arguments by supplying an overt inflectional element (the definite article) before the noun. The consistency and systematicity with which the definite article occurs in Greek can guide the L2 learner into acquiring definite articles. In contrast, clitic pronouns are derivationally more complex and do not consistently appear before their verbal host, as they are discourse dependent. The appearance of clitics in noncanonical argument positions coupled with their derivational complexity could give rise to their delayed acquisition pattern. This account predicts that L2-TD children do not have problems understanding that clitics are arguments unlike the predictions of the IH; the problems lie in spelling them out in a noncanonical argument position.

\section{Comprehension of grammatical morphology in children with SLI and L2-TD children}

The above studies from monolingual children with SLI and L2-TD children point toward the problematic nature of definite articles and clitic pronouns in both populations. However, the source of the problem is different for the L1-SLI and the L2-TD children. First, L2-TD children have intact language processing and acquisition systems and develop their L1 in a typical manner before they are exposed to the L2 around the age of 3 or 4 years (Meisel, 2008; Schwartz, 2003). Conversely, children with SLI have been shown to possess less efficient processing (Montgomery \& Leonard, 2006) or language learning systems (Paradis \& Gopnik, 1997; Ullman \& Gopnik, 1999). Second, the linguistic experience of monolingual and bilingual children differs considerably. L2-TD children usually receive less input in the L2 than monolingual children, and L2-TD children with fewer than 3 years of L2 exposure have been shown to resemble monolingual children with an impaired developmental profile (Genesee, Paradis, \& Crago, 2005). Third, the nature of the L1 may influence L2 acquisition, especially when the structures acquired in the L2 are not present in the L1 (Grüter \& Crago, 2012; Zdorenko \& Paradis, 2011), as in the case of Turkish-speaking children acquiring articles and clitics in Greek, morphosyntactic elements that are missing in Turkish. 
Chondrogianni et al.: Production and processing in L2 and SLI children

Recent studies directly comparing production and off-line comprehension or metalinguistic judgment of morphosyntactic abilities in children with SLI and L2 children have shown differences between the two populations (Grüter, 2005; Paradis et al., 2008). To date, the only on-line comprehension study comparing directly the two populations is the one by Marinis and Saddy (2013) that examined on-line and off-line comprehension of English actives and passives, but currently there are no studies directly comparing L2 and SLI children's production and sensitivity to morphosyntactic violations using an on-line comprehension task.

On-line comprehension studies can provide us with a window into the underlying representations and processing routines of language learners (Clahsen, 2008; Marinis, 2010; Snedeker, 2009). On-line sentence comprehension requires drawing information from multiple levels of linguistic representation to construct syntactic analyses (Snedeker, 2009; Trueswell, Sekerina, Hill, \& Logrip, 1999). Performance on on-line comprehension tasks can be modulated by whether the necessary linguistic representations are available to the child but can also be compromised due to processing limitations related to lack of speed and automaticity.

In a series of studies, Montgomery and Leonard (1998, 2006) and Leonard, Miller, and Finneran (2009) reported that children with SLI had significantly longer reaction times (RTs) than their age-matched TD peers when comprehending sentences in real time, and they were not able to detect the grammatical violations induced by omission of grammatical morphemes with low phonetic substance, such as third person $-s$, and past tense - $e d$ in English, compared with grammatical morphemes of high phonetic substance, such as -ing, in contrast with their agematched TD peers. Following the surface account, the inability of the children with SLI to detect the grammatical violations related to morpheme omission was attributed to processing limitations coupled with the grammatical properties of these morphemes (Leonard et al. 2009).

Turning to L2 acquisition, performance on on-line sentence comprehension tasks and the ability to detect morphosyntactic anomalies has been shown to be susceptible to proficiency effects, especially in adult L2 learners (VanPatten, Keathing, \& Leeser, 2012). In addition, processing speed and automaticity have been shown to be related to vocabulary size (Bialystok, Craik, \& Luk, 2008; Segalowitz \& Hulstijn, 2005). Studies examining on-line processing of morphosyntax in L2-TD children have shown that L2-TD children are able to process the grammatical violations induced by omitted or erroneous morphemes despite slow speed, smaller vocabularies, and production limitations (Blom \& Vasić, 2011; Chondrogianni \& Marinis, 2012; Vasić \& Blom, 2011).

Chondrogianni \& Marinis (2012) compared the production and on-line comprehension of tense morphemes (third person $-s$, past tense $-e d$ ) by Turkish-speaking children acquiring English as L2 using a modified version of the on-line processing task by Montgomery and Leonard (1998, 2006). The results showed that the L2-TD children were sensitive to the grammatical violations related to the omission of tense morphemes in the on-line comprehension task despite variable production of the same morphemes and despite having longer RTs than their L1 peers. This is in contrast with the previous findings by Montgomery and Leonard 
$(1998,2006)$ with children with SLI, who were not sensitive to the omission of tense morphemes. Sensitivity to grammatical violations during an on-line task despite variable production has been found in studies examining the nominal domain in Dutch L2-TD children (Blom \& Vasić, 2011; Vasić \& Blom, 2011; Vasić, Chondrogianni, Marinis, \& Blom, 2012). In all of these studies, the L2-TD children had at least 3 years of exposure to the $\mathrm{L} 2$.

Chondrogianni and Marinis (2012) interpreted the L2-TD children's ability to detect the grammatical violations related to missing or erroneous morphology despite variable production as evidence for the missing surface inflection hypothesis (MSIH; Haznedar \& Schwartz, 1997; Prévost \& White, 2000). According to the MSIH, L2 learners' problems with grammatical morphology are output related and do not indicate impaired underlying grammatical representations. These output problems are unique to production and may be caused by lexical access and retrieval problems (Bialystok et al., 2008), prosodic differences between languages (Goad \& White, 2006), lack of automaticity or a combination of these factors.

To date there are no studies that directly compare children with SLI with TD L2 children using a combination of production and on-line processing tasks to examine morphosyntax.

\section{THE PRESENT STUDY}

In this study we directly compared production and on-line comprehension of definite articles and clitic pronouns by L2-TD children and L1-SLI. We focused on L2-TD children at initial stages of acquisition to examine whether the difficulties that L2-TD children have with articles and clitics are related to output problems or represent problems with underlying grammatical structures. We postulated that the more sensitive and implicit on-line comprehension tasks used in the study might help us differentiate between L2-TD children and children with SLI more successfully compared with production tasks. We addressed the following research questions:

1. Do L2-TD children and L1 children with SLI differ in terms of accuracy and error patterns in the production of definite articles in different syntactic contexts (subject, object) and clitic pronouns?

2. Do the same L2-TD children and L1 children with SLI differ when processing the grammatical violations induced by definite article and clitic pronoun omission in an on-line processing task?

3. Does the performance on articles and clitic pronouns differ in the production and the on-line comprehension task for the L1-SLI and the L2-TD children?

\section{Predictions}

For the children with SLI. According to the IH (Tsimpli, 2001; Tsimpli \& Mastropavlou, 2008; Tsimpli \& Stavrakaki, 1999), definite articles and clitic pronouns will be problematic for Greek children with SLI since they carry uninterpretable features. This difficulty will be manifested as impaired production of definite 
Chondrogianni et al.: Production and processing in L2 and SLI children

articles and clitic pronouns. However, school-aged children who have received extensive treatment may perform well on these two structures because of learning rather than automatization of rule application (Paradis \& Gopnik, 1997). In the present paper, we hypothesize that lack of automatization of rule application may be manifested more clearly in the on-line comprehension task which taps into real-time implicit knowledge. The production task is also an on-line task that requires automaticity in lexical retrieval and articulation. However, the production task that we employed in the present study was not time constrained and children had ample time to reflect and respond, which may lead to the use of metalinguistic knowledge.

According to the CGCH (Stavrakaki \& van der Lely, 2010), Greek children with SLI will have optional performance on clitics since they require movement at the sentential level and chain formation. In contrast, definite articles will not be impaired because they involve a local relation between the determiner and the noun. Production will be on a par with comprehension.

According to the surface account (Leonard et al., 1997), Greek children with SLI will have equal problems producing definite articles and clitic pronouns and processing the grammatical violations related to their omission, as these two elements are morphophonologically similar and they have the same low phonetic salience.

For the L2-TD children. According to the $\mathrm{IH}$, the acquisition of definite articles and clitic pronouns will be problematic for Turkish-speaking children with Greek as L2. In this account, Greek L2-TD children will not acquire case and argument licensing in Greek in the same way as Greek L1 children. As a result, L2-TD children may exhibit variable production of definite articles and clitic pronouns. Later high production of the definite article and the clitic pronoun could be achieved, but this does not indicate that L2-TD children have L1-like representations of these two D-elements. Problems in production and with underlying representations will be particularly evidenced in the case of clitics that are derivationally more complex and do not enter into a local relationship with the agreeing noun. Furthermore, their realization is dependent upon discourse properties, which makes their use less consistent than that of definite articles that obligatorily precede nouns in argument positions.

According to the feature reassembly account (Lardiere, 2005, 2009) and the MSIH (Haznedar \& Schwartz, 1997), low production will not indicate impaired underlying representations, in contrast to the $\mathrm{IH}$. Both the feature reassembly account and the MSIH predict that the L2-TD children will be sensitive to the omission of definite articles and clitic pronouns, even though they are omitted in production. Within the feature reassembly account, the systematicity and the locality of occurrence of the definite article in relation to the clitic can affect the L2 acquisition pattern, as these factors relate to the nature and the context of occurrence of the morphophonological exponents.

Comparing L2-TD children and children with SLI on production and on-line comprehension. Previous studies with L2-TD children with limited exposure have shown that their production of definite articles and clitic pronouns is low (Chondrogianni, 
2008a, 2008b). Studies with school-aged children with SLI have shown that they can overcome problems with these two D-elements at a school age given sufficient treatment (Smith, 2008; Stavrakaki, 2001; Tsimpli \& Mastropavlou, 2008). Therefore, we expect L2-TD children to have low production of definite articles and clitics, whereas we expect the school-aged children with SLI in our study to have high production of articles and clitics. L2-TD children may also show sensitivity to the grammatical violation induced by article and clitic omission following previous studies showing a similar dissociation between production and on-line comprehension (Blom \& Vasić, 2011; Chondrogianni \& Marinis, 2012). We also expect that if children with SLI have not internalized the morphophonological and syntactic properties of articles and clitics, they should not exhibit sensitivity to the omission of these elements in the on-line comprehension task.

Finally, we expect both L2-TD children and children with SLI to have higher production on definite articles than on clitics following previous studies (Chondrogianni, 2008a, 2008b; Smith, 2008; Tsimpli \& Mastropavlou, 2008) and given the difference in derivational complexity between the two D-elements (Chondrogianni, 2008a, 2008b; Mavrogiorgos, 2010).

\section{Methodology}

Participants. Twenty TD Turkish-speaking children learning Greek as an L2, 16 L1 Greek-speaking children with SLI, and 31 L1-TD Greek-speaking children participated in the study (total $=67$ participants). The L2-TD children were recruited in the northeastern part of Greece (Thrace), which has a bilingual (Turkish-Greek) community. They did not have any reported speech or language difficulties. The children with SLI were recruited through speech and language therapists (SLTs) and through the Athens University Children's Hospital in Athens. They were diagnosed as having persistent difficulties with language development by speech therapists on the basis of both clinical assessment and results on standardized and nonstandardized tests of language abilities. Exclusion criteria for all groups was performance below one standard deviation on Raven's Coloured Matrices (Raven, 1998), a history in hearing impairment, frank neurological impairment, psychoemotional disturbance, and diagnosis of autism. One L1-TD child scored below one standard deviation on the Raven's Coloured Matrices and was therefore excluded from the study. At the time of testing, all L1-SLI children had speech and language therapy between 1 and 3 years. The L1-TD children were recruited from schools in Athens and did not have any reported speech or language difficulties.

The L2-TD children had a mean age of 7;6 at the time of testing ( $S D=10.6$, range $=5 ; 9-8 ; 10)$, the L1-SLI had a mean age of $6 ; 8(S D=9.9$, range $=5 ; 6-8 ; 4)$ and the L1-TD children a mean age of 7;3 ( $S D=10.1$ months, range $=6 ; 0-$ 8;6). Post hoc comparisons using Bonferroni correction showed that the L1-TD children were matched on age with the L2-TD children and the children with SLI (L1-TD vs. L2-TD: $p=1$; L1-TD vs. L1-SLI: $p>.1$ ). The L2-TD children were significantly older than the L1-SLI children $(p<.05)$.

The L2-TD children were tested in their homes by a bilingual research assistant familiar with the local community who elicited information from parents and caregivers regarding the children's language history and status, the age of onset, 
Chondrogianni et al.: Production and processing in L2 and SLI children

Table 1. Results from the DVIQ and the Raven's CPM

\begin{tabular}{lccc}
\hline \hline & $\begin{array}{c}\text { L2-TD } \\
(N=20)\end{array}$ & $\begin{array}{c}\text { L1-SLI } \\
(N=16)\end{array}$ & $\begin{array}{c}\text { L1-TD } \\
(N=30)\end{array}$ \\
\hline Task & & & \\
DVIQ & 21.6 & 21.5 & 27.5 \\
Mean & $15-28$ & $15-28$ & $23-30$ \\
Range & 3.6 & 3.9 & 1.6 \\
SD & & & \\
CPM & 109.6 & 101 & 110.5 \\
Mean & $85-125$ & $85-125$ & $85-125$ \\
Range & 11.5 & 11.4 & 11.9 \\
SD & & & \\
\hline \hline
\end{tabular}

Note: DVIQ, Diagnostic Verbal IQ Test for Preschoolers; CPM, Coloured Progressive Matrices; L2, second language; TD, typically developing; L1, first language; SLI, specific language impairment.

and years of exposure to Greek. All L2-TD children's parents and caregivers were Turkish speaking. The L2-TD children's systematic exposure to Greek begun at preschool (at the age of 4 or 5 years) or primary school entrance (at the age of 6 years). The mean age of the start of Greek exposure was 5;5 years $(S D=$ 10 months, range $=4 ; 0-6 ; 6)$ and the mean length of exposure to Greek was 21 months $(\mathrm{SD}=14$ months, range $=6-54$ months). The L1-SLI children were tested in their homes or at the SLTs' practices. The L1-TD children were tested in their schools.

Baseline verbal and nonverbal tasks. To compare the language abilities of the three groups we used the comprehension of morphosyntax from the Diagnostic Verbal IQ Test for Preschoolers by Stavrakaki and Tsimpli (2000). In this task, children are presented with a three-picture panel, they listen to a sentence and they are asked to indicate which picture matches the sentence they heard. This is not a standardized task, and therefore, raw scores were used for further statistical comparisons. The children's nonverbal IQ was assessed through Raven's Coloured Progressive Matrices (Raven, 1998). Raw scores were converted into standard scores.

Post hoc tests with Bonferroni correction showed that the L2-TD children and the L1-SLI children were matched on their language abilities on the basis of the Diagnostic Verbal IQ Test for Preschoolers $(p>.1)$; both groups had significantly lower scores than the L1-TD group in terms of language abilities (L1-TD vs. L2TD: $p<.001$; L1-TD vs. L1-SLI: $p<.001)$. Although the L1-SLI children had significantly lower scores than the L1-TD children on nonverbal abilities (L1-TD vs. L1-SLI: $p<.05)$, they did not differ from the L2-TD children $(p=.08)$. The L2-TD children also did not differ in their nonverbal abilities from the L1-TD children $(p>.1$; Table 1$)$. 
Experimental tasks.

PRODUCTION TASKS. To assess the children's production on definite articles we developed a task similar to the definite article elicitation subtest of Seymour, Roeper, de Villiers, and de Villiers (2005) with short stories without picture props. In this task, children listen to short stories, and they are asked to provide answers to the question "Guess which?," which elicits definite specific NPs, as in Examples (7) and (8).

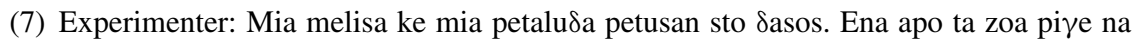

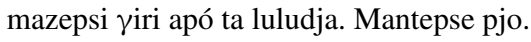

Experimenter: A bee and a butterfly were flying in the forest. One of the animals went to get pollen from the flowers. Guess which!

Child (expected response): I.FEM.NOM melisa.

Child (expected response): The bee.

(8) Experimenter: I Maria ixe enan pinaka ke ena trenaki. Kremase ena apo ta fio ston tixo tu Somatiu tis. Mantepse pjo.

Experimenter: Mary had a painting and a train. She hung one of the two on her bedroom wall. Guess which!

Child (expected response): Ton.MASC.ACC pínaka.

Child (expected response): The painting.

The production of Greek definite articles was elicited in two syntactic positions, namely in the subject position, as in Example (7), and in the object position, as in Example (8). In Greek the NP in the subject condition is nominative case marked, and in our sentences it was the subject of the intransitive verb that appeared in the lead-in sentence. In the object condition, the elicited NP was the object of the transitive verb in the lead-in sentence and was marked with accusative case. The elicited nouns in the subject condition were animate (bee, bird, frog, hen, mouse, turtle) and in the object condition inanimate (ball, book, doll, painting, tie, train). This is because prototypically subjects are animate and objects are inanimate. The nouns in the two conditions were matched for frequency on the basis of the Hellenic National Corpus and length (number of syllables). All nouns and verbs were also included in the textbooks used for teaching Greek in primary schools (Institute for Language and Speech Processing, 2001). There were 6 items per condition (subject, object) and 12 filler items, for a total of 24 items.

To elicit third person direct object clitic pronouns, we used a picture-based elicitation task following Schaeffer (2000) and Chondrogianni (for Greek; 2008a, 2008 b). In this task, children are first presented with a picture showing two participants. They are then shown another picture with the same participants engaging in an activity involving a transitive action and are asked the question "What is $X$ doing to $Y$ ?," which elicits a transitive verb with a clitic pronoun, as in Example (9).

(9) Experimenter (first picture): Kita! E $\delta$ o ine ena ljontari ke ena elafi. To ljontari pinai poli. 
Chondrogianni et al.: Production and processing in L2 and SLI children

Experimenter (first picture): Look! Here is a lion and a deer. The lion is very hungry! Experimenter (second picture): Kita e $\delta$ o tora! Ti kani to ljontari sto elafi?

Experimenter (second picture): Look here, what is the lion doing to the deer?

Child (expected response): To.CLIT dagoni.

Child (expected response): It is biting it.

All nouns used in the elicitation task for clitics were animate and depicted animals. There were five depictable transitive verbs (kiss, kick, hug, bite, pinch) and 10 animal characters (bear, cat, deer, elephant, goat, lion, monkey, rabbit, sheep, wolf) as arguments of the verbs.

Coding and scoring. In the case of definite articles, scoring proceeded as follows. Responses involving a definite article and the target noun, that is, the noun that had already been introduced in the story, were coded as "correct." Responses that involved an indefinite article with the target noun were coded as "substitutions." Responses with bare (articleless) target nouns were coded as "omissions." If a child produced a noun not already mentioned in the story with or without an article, then this response was coded as "other" and was excluded from the final calculation. Definite articles with erroneous number, gender, or case feature specifications were considered target responses for the purposes of this study and were included in the "correct" category. This was because we were interested in the production versus omission of the two D-elements regardless of their target morphology.

In the case of clitic pronouns, target responses involved a transitive verb preceded by a clitic pronoun. Responses involving full lexical NPs, for example, the lion is biting the deer, were counted as "substitutions," and sentences with no object, for example, he is biting, were counted as "omissions." Clitic pronouns with erroneous number or gender feature specification were considered target responses and were included in the "correct" category. If a child responded with a different transitive verb than the one in the elicitation question, then this context was still considered felicitous for eliciting a clitic pronoun and was included in the calculation.

For both articles and clitics, proportion correct, omissions, and substitutions were calculated out of the three responses (denominator: sum of correct, substitutions, and omissions).

Self-paced listening task. To assess the children's ability to process the omission of definite articles and clitics in real-time, we used an on-line self-paced listening task. Self-paced listening tasks measure the children's RTs by pressing a button to listen to sentences word-by-word or phrase-by-phrase. They can be used with (e.g., Marinis \& Saddy, 2013) or without picture verification (present study). They are child friendly and can easily be used with participants who have language impairment and/or process sentences at a slower rate, because they have control over the pace of the auditory stimuli. This is in contrast to cross-modal priming (e.g., Marinis \& van der Lely, 2007) and word-monitoring tasks (e.g., Montgomery \& Leonard, 1998, 2006) that are challenging because they are speeded and children cannot control the pace of presentation. For a discussion about the usefulness of RT experiments with language impaired populations, see Marinis (2008, 2010). 
In this self-paced listening task, half of the sentences were grammatical and included definite articles and clitic pronouns and the other half of the sentences contained omissions of these elements. The sentences involved stories about animals engaging in imaginary activities. At the beginning of each trial, children saw a picture on a computer screen and at the same time they listened to a lead-in sentence introducing the participants (animals) or objects in the picture. The leadin sentence was followed by the critical sentence that was segmented into phrases. To hear the critical sentence, children were instructed to press a response button as fast as they can in an E-prime box. One-third of the sentences was followed by a comprehension question to make sure that the children were attending to the task. These comprehension questions did not examine comprehension of the experimental structures. The experiment was programmed and controlled by the software E-prime (Schneider, Eschmann, \& Zuccolotto, 2002). Examples (10)(12) illustrate the grammatical and ungrammatical sentences in the experimental conditions.

(10) Definite article-subject position

Xtes ena delfıni epeze sti $\theta$ alasa me ta ala zoa. Arya / to apoyevma / (to) delfini / kini

Yesterday a dolphin was playing in the sea with the other animals. Late / in the afternoon / (the) dolphin / chased / the fish.

(11) Definite article-object position

Xtes ena kanguro epeze me mia prasini bala. To kanguro / klotsise / (ti) bala / sto

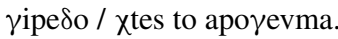

Yesterday a kangaroo was playing with a green ball. The kangaroo / kicked/(the) ball / on the pitch / yesterday afternoon.

(12) Direct object clitic pronoun

To ljontari iӨele na fai to elafi. To elafi / tromakse polí / otan / to ljontari / (to) Sagose / sti zugla / pano stus vraxus.

The lion wanted to eat the deer. The deer / got very scared / when / the lion / (it) bit / in the jungle / on the rocks.

The grammatical and ungrammatical versions of each sentence were recorded separately to avoid the disruption in the intonation of the sentences that would have occurred if we spliced out the article or the clitic from the grammatical versions of each sentence. This ensured that the grammatical and ungrammatical sentences had the same natural intonation. Moreover, in the case of clitics, we used falling intonation at the verb to indicate an intonation phrase boundary. This was to ensure that children did not expect any further arguments after the verb. If TD children and children with SLI are sensitive to the grammatical violations induced by the omission of articles and pronouns, then their RTs are predicted to be longer in the critical segment of the ungrammatical compared to the grammatical sentences.

There were 8 critical nouns per sentence type, which appeared only once across the sentence types. This produced 24 critical nouns in total (16 animate, 8 inanimate). The overall number of animate and inanimate nouns was controlled for in the whole experiment, as was the number of NPs containing an article and bare nouns (licit or illicit). The nouns in the critical conditions were matched for 
frequency and length in numbers of syllables following the same resources as in the production task. The critical sentences in the article conditions comprised five segments and the critical segment was Segment 3. The conditions with clitics involved accusative clitic pronouns that were direct objects of transitive verbs. Seven transitive verbs were used (kiss, kick, chase, hug, bite, push, throw), and 10 animal characters were used as arguments of the verbs. All verbs appeared in the perfective aspect, which has been found to elicit a higher production rate of overt arguments compared to the imperfective aspect (Chondrogianni, 2008a; Tsimpli $\&$ Papadopoulou, 2006). The critical sentences in the clitic pronoun conditions had seven segments and the critical segment was Segment 5.

The experiment consisted of 68 experimental trials ( 8 per condition for articles and 10 per condition for clitic pronouns, half grammatical and half ungrammatical) and eight fillers, which consisted of sentences with licit bare objects in the form of mass nouns. We used a single-case design; that is, each participant encountered the grammatical and ungrammatical version of each sentence in a different list.

Two lists of 34 items were created that differed in the order of the items. Each participant saw both lists at weekly intervals. The presentation of the lists was randomized across participants in order to control for any sequencing effects. The experimental session was preceded by a practice session in which the children were familiarized with the task. In order to proceed to the experimental session, the children had to successfully complete the practice session, which could be repeated twice. No child failed to complete the practice session.

\section{Procedure}

Each child participated in three sessions. In the first session, the baseline and production tasks were administered. In the following two sessions the on-line processing tasks were carried out. Production tasks always preceded on-line comprehension tasks to avoid making participants aware of the phenomena being examined by exposing them to the sentences with grammatical violations within the on-line comprehension task. Each session lasted up to one hr depending on the child's age and language abilities.

\section{RESULTS}

To calculate within-subjects effects across the three groups we used repeatedmeasures analyses of variance (ANOVAs). For all ANOVAs, effect sizes were computed using a partial eta-square $\left(\eta_{\mathrm{p}}^{2}\right)$. Post hoc tests were calculated using Bonferroni correction. To unpack interactions, we ran paired-samples $t$ test for each group separately. Effect sizes for $t$ tests were calculated using a Cohen $d$. Thresholds of $0.20,0.50$, and 0.80 were used for small, moderate, and large effect sizes, respectively (Cohen, 1992).

\section{Production}

To examine between-group differences in the production of definite articles depending on syntactic position, we calculated the children's accuracy in the 


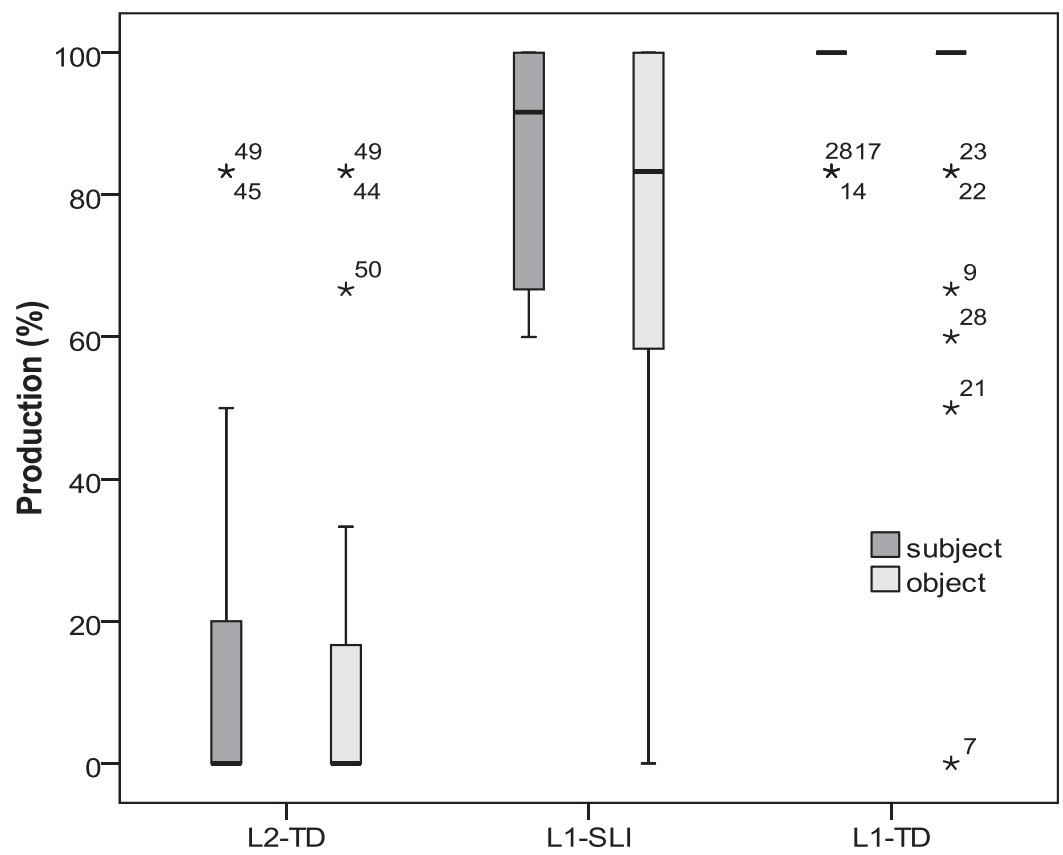

Figure 1. Production (\%) of definite articles in the subject and the object position by typically developing sequential bilingual (L2-TD) children, monolingual children with specific language impairment (L1-SLI), and L1-TD children.

production of definite articles in the subject and in the object position, respectively, as shown in Figure 1.

To determine statistical significance, a repeated-measures ANOVA was run with Position (subject, object) as the within-subjects factor and Group (L2-TD, L1-SLI, L1-TD) as the between-subjects factor. This revealed a main effect of Position, $\left.F(1,63)=6.41, p<.05, \eta_{\mathrm{p}}^{2}=0.09\right)$, because overall there were more definite articles produced in the subject than in the object position, and a main effect of Group, $F(1,63)=98.89, p<.001, \eta_{\mathrm{p}}^{2}=0.76$, indicating that the three groups differed in terms of accuracy. Consecutive post hoc tests with Bonferroni correction revealed that the L1-TD and the L1-SLI groups had significantly higher accuracy than the L2-TD group ( $p<.001$ in both cases). There was no difference between the L1-TD children and the L1-SLI children.

Subsequently, we calculated the types of errors that children produced, when not producing the target form. Figure 2 presents the proportion of substitution and omission errors in the subject and the object position for each group separately.

To examine whether the three groups differed in the types of errors that they committed in each syntactic position, we ran a repeated-measures ANOVA with Position (subject, object) and Error Type (substitutions, omissions) as the withinsubjects factors and Group (L2-TD, L1-SLI, L1-TD) as the between-subjects 
Chondrogianni et al.: Production and processing in L2 and SLI children

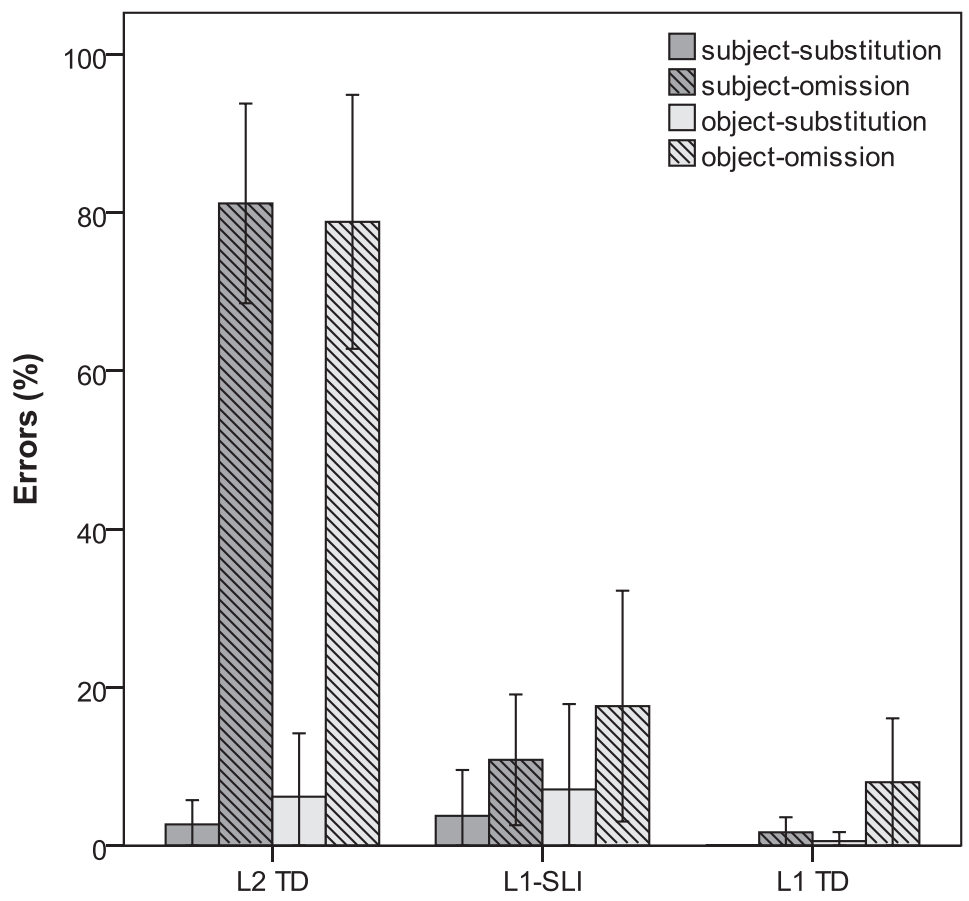

Figure 2. Substitution and omission errors (\%) in the subject and the object position by typically developing sequential bilingual (L2-TD) children, monolingual children with specific language impairment (L1-SLI), and L1-TD children.

factor. This revealed a main effect of Position, $F(1,63)=5.22, p<.05$, $\eta_{\mathrm{p}}^{2}=0.08$, a main effect of Error Type, $F(1,63)=7.77, p<.001, \eta_{\mathrm{p}}^{2}=$ 0.58 , a main effect of Group, $F(1,63)=101.81, p<.001, \eta_{\mathrm{p}}^{2}=0.76$, and a significant interaction between Error Type and Group, $F(2,63)=54.69, p<$ $.001, \eta_{\mathrm{p}}^{2}=0.64$, suggesting that the three groups differed in the types of errors that they committed.

To unpack the interaction between error type and group, we ran paired-samples $t$ tests with Error Type (substitutions, omissions) as the within-subjects factor for each group separately. For the L2-TD group, the predominant error type was omissions (omissions: $80 \%$; substitutions: $4.4 \%$ ) $t(19)=9.6, p<.001, d=3.4$. For the L1-SLI children, there was no significant difference between the two error types (omissions: $14.2 \%$; substitutions: $5.4 \% ; p>.2$ ). For the L1-TD group, there were more omissions $(4.8 \%)$ than substitutions $(0.3 \%) t(29)=2.16, p<.05$, $d=0.57$.

Consecutive post hoc comparisons using Bonferroni correction revealed that the L2-TD children had significantly more omissions than the L1-TD and the L1-SLI groups $(p<.001$ in both cases) but the groups did not differ from each other in 
Chondrogianni et al.: Production and processing in L2 and SLI children

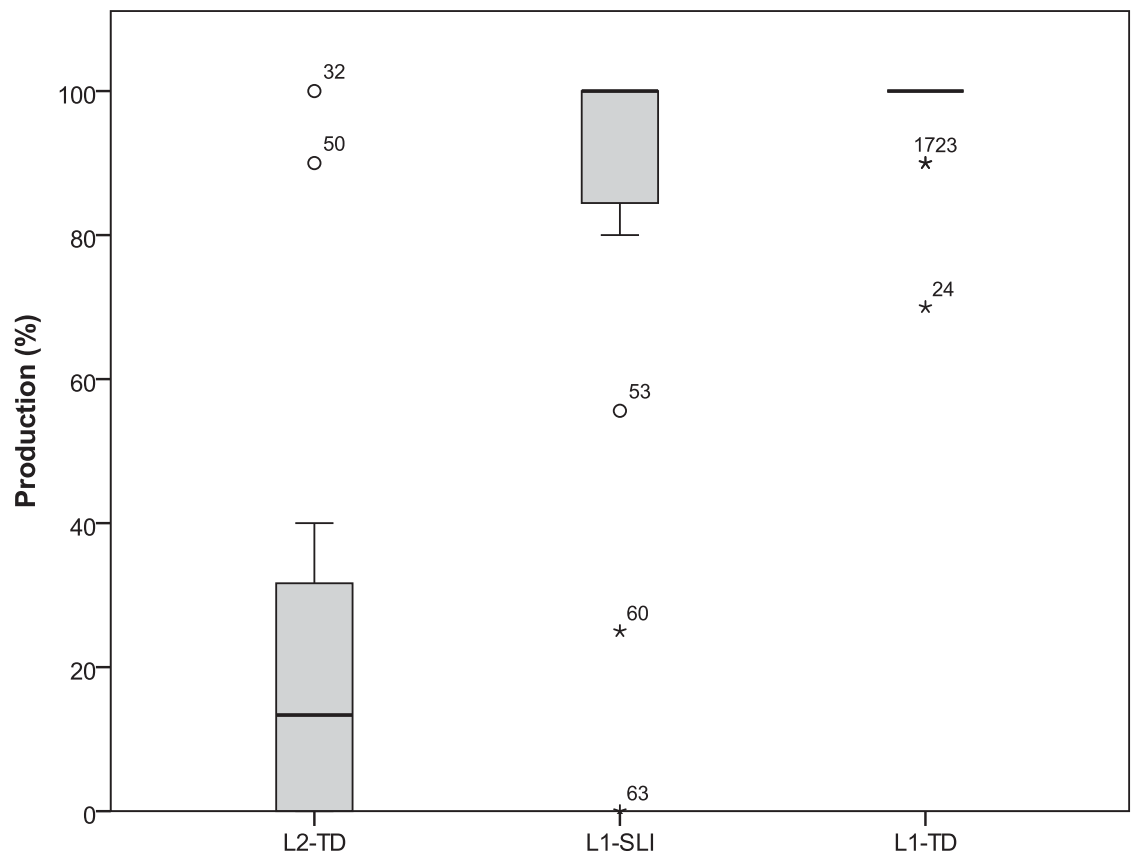

Figure 3. Production (\%) of clitic pronouns by typically developing sequential bilingual (L2TD) children, monolingual children with specific language impairment (L1-SLI), and L1-TD children.

terms of substitutions. The L1-TD and the L1-SLI children did not differ from each other in terms of error types.

Subsequently, we calculated the children's accuracy on the production of clitic pronouns, as well as the types of errors they committed. These were substitutions of the clitic pronoun by a full lexical NP and omissions of the clitic (Figures 3 and 4).

To examine whether the three groups differed in their accuracy on object clitic pronouns we ran a one-way ANOVA on children's accuracy rates with Group (L2TD, L1-SLI, L1-TD) as the between-subjects factor. This showed a significant difference between the groups, $F(1,63)=76.05, p<.001, \eta_{\mathrm{p}}^{2}=0.71$. Post hoc comparisons using Bonferroni correction revealed that the L2-TD group produced significantly fewer clitics than the L1-TD and the L1-SLI groups ( $p<.001$ in both cases).

To examine whether the three groups differed in terms of error types, we ran a repeated-measures ANOVA with Error Type (substitutions, omissions) as the within-subjects factor and Group (L2-TD, L1-SLI, L2-TD) as the betweensubjects factor. This revealed a main effect of Error Type, $F(1,63)=101.84, p<$ $.001, \eta_{\mathrm{p}}^{2}=0.62$, a main effect of Group, $F(1,63)=76.05, p<.001, \eta_{\mathrm{p}}^{2}=0.71$, and a significant interaction between Error Type and Group, $F(1,63)=74.6$, 
Chondrogianni et al.: Production and processing in L2 and SLI children

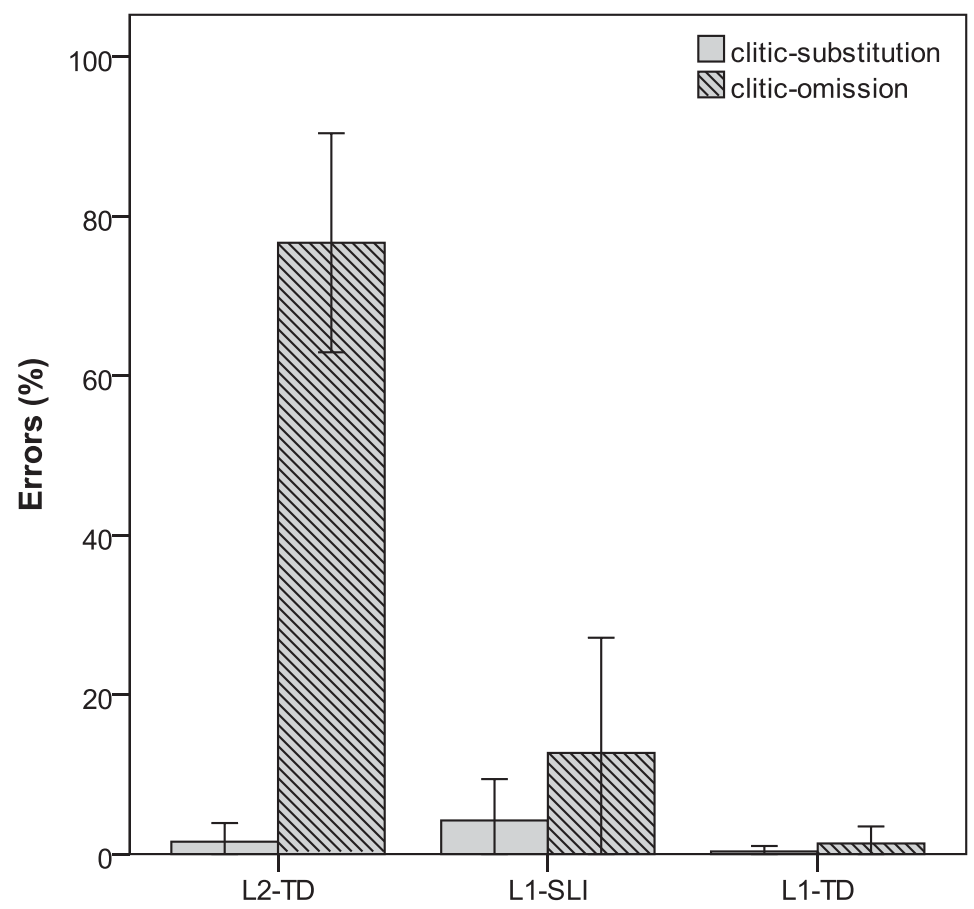

Figure 4. Substitution and omission errors (\%) errors (\%) of clitic pronouns by typically developing sequential bilingual (L2-TD) children, monolingual children with specific language impairment (L1-SLI), and L1-TD children.

$p<.001, \eta_{\mathrm{p}}^{2}=0.73$, suggesting that the three groups performed differently in terms of error types.

To unpack the interaction between Error Type and Group we ran paired-sample $t$ tests with Error Type (substitutions, omissions) as the within-subjects factor for each group separately. This revealed a main effect of Error Type only for the L2-TD group, $t(19)=-10.87, p<.001, d=-3.57$, as there were significantly more omissions $(76.7 \%)$ than substitutions $(1.6 \%)$, but not for the L1-TD group (substitutions: $0.3 \%$; omissions: $1.3 \% ; p>.3$ ) or the L1-SLI group (substitutions: 4.2\%; omissions: $12.7 \% ; p>.2$ ).

Post hoc comparisons using Bonferroni correction showed that the L2-TD children had significantly more errors of omission than the L1-TD and the L1-SLI children ( $p<.001$ in both cases), but they did not have more substitution errors. The L1-SL1 children differ not from the L1-TD children in terms of substitutions $(p=.08)$.

Subsequently, we examined whether the children's performance differed depending on the type of DP produced (i.e., articles and clitic pronouns). To that end, we aggregated the scores from the definite articles in the subject and the object position, giving rise to a single score on definite articles. For the L2-TD children 
the overall accuracy of definite articles was $15.7 \%(S D=27.1$, range $=0 \%-$ $83.3 \%)$, for the L1-SLI children it was $81.3 \%(S D=22.5$, range $=33.3 \%-100 \%)$, and for the L1-TD children it was $94.8 \%(S D=11$, range $=50 \%-100 \%)$.

A repeated-measures ANOVA with DP type (article, clitic) as the withinsubjects factor and Group (L2-TD, L1-SLI, L1-TD) as the between-subjects factor showed a main effect of Group, $F(1,63)=149.38, p<.001, \eta_{\mathrm{p}}^{2}=0.83$. Post hoc comparisons using Bonferroni correction showed that the L2-TD children had significantly lower accuracy than the L1-TD and the L1-SLI children $(p<.001$ in both cases), who in turn, had lower accuracy than the L1-TD children $(p<.01)$. We did not find an effect of DP type or any interactions.

Self-paced listening task. Raw RTs were transformed into residual RTs in order to control for the difference in length between the critical segments in the grammatical and ungrammatical conditions. Extreme values were calculated using the boxplot procedure in Statistical Package for the Social Sciences. This revealed that residual RTs above $2000 \mathrm{~ms}$ constituted extreme values and were excluded from the final calculation as extreme values. Outliers were defined as RTs of $2 S D$ above or below the means per condition per subject and per item. Outliers were replaced with the mean per participant and per item per condition. The total proportion of extreme values and outliers was $4 \%$ for the L2-TD children, 5\% for the L1-SLI, and 3\% for the TD children.

Accuracy to comprehension questions was $78.9 \%$ for the L2-TD children $(S D=$ 9.6, range $=61.5 \%-100 \%), 82.6 \%$ for the L1-SLI children $(S D=15.3$, range $=$ $55 \%-100 \%$ ), and $91.8 \%$ for the L1-TD children $(S D=7.3$, range $=78.7 \%-100 \%)$. Post hoc tests using Bonferroni correction revealed that the L2-TD children $(p<$ $.001)$ and the L1-SLI children $(p<.05)$ had significantly lower accuracy in the comprehension questions than the L1-TD children. The L2-TD and L1-SLI children did not differ from each other $(p>.1)$. Items with erroneous responses to the comprehension questions were excluded from the analyses of RTs.

Definite articles. The residual RTs for the definite article in the subject and object positions for L2-TD, L1-SLI children, and L1-TD are presented in Tables 2 and 3, respectively. To examine whether the L2-TD, the L1-SLI, and the L1-TD children were sensitive to the grammatical violations due to article omission in the subject and the object position, we ran a repeated-measures ANOVA with Position (subject, object) and Grammaticality (grammatical, ungrammatical) as the within-subjects factors and Group (L1-TD, L2-TD, L1-SLI) as the betweensubjects factor in a per participants $\left(F_{1}\right)$ and a per items $\left(F_{2}\right)$ analysis for each segment separately. We report the results from the precritical, the critical, and the postcritical segments. The precritical segment is crucial to investigate whether an effect of grammaticality in the critical segment is caused by an effect of grammaticality earlier on in the sentence. The postcritical segment can reveal spill-over effects.

For the precritical segment (Segment 2), there was a main effect of Position, $F_{1}(1,63)=13.29, p=.001, \eta_{\mathrm{p}}^{2}=0.17 ; F_{2}(1,21)=23.8, p<.001, \eta_{\mathrm{p}}^{2}=0.53$; a main effect of Group, $F_{1}(1,63)=6.27, p<.01, \eta_{\mathrm{p}}^{2}=0.17 ; F_{2}(1,21)=15.12$, 
Table 2. Mean (standard deviation) residual reaction times and mean differences (critical segment) for the grammatical and ungrammatical sentences for definite articles in the subject position by L2-TD, L1-SLI, and L1-TD children

\begin{tabular}{|c|c|c|c|c|c|c|c|}
\hline \multirow[b]{2}{*}{ Group } & \multicolumn{2}{|c|}{$\begin{array}{l}\text { Segment } 2 \\
\text { (Precritical) }\end{array}$} & \multicolumn{2}{|c|}{$\begin{array}{c}\text { Segment } 3 \\
\text { (Critical) }\end{array}$} & \multicolumn{2}{|c|}{$\begin{array}{c}\text { Segment } 4 \\
\text { (Postcritical) }\end{array}$} & \multirow{2}{*}{$\begin{array}{c}\begin{array}{c}\text { Mean Differ. } \\
\text { (Critical Segment) }\end{array} \\
\text { Ungr. - Gram. }\end{array}$} \\
\hline & Gram. & Ungr. & Gram. & Ungr. & Gram. & Ungr. & \\
\hline L2-TD & 357 (114) & 333 (97) & $389(121)$ & 444 (104) & $666(106)$ & $633(94)$ & 55 \\
\hline L1-SLI & $340(254)$ & 387 (187) & $361(281)$ & 457 (195) & $622(257)$ & $651(263)$ & 96 \\
\hline L1-TD & $283(114)$ & 275 (119) & 281 (119) & $358(128)$ & $520(116)$ & $515(143)$ & 77 \\
\hline
\end{tabular}

Note: Mean differences are calculated by subtracting the mean reaction times on the grammatical condition from the mean reaction times on the ungrammatical condition. L2, second language; TD, typically developing; L1, first language; SLI, specific language impairment. 
Table 3. Mean (standard deviation) residual reaction times and mean differences (critical segment) for the grammatical and ungrammatical sentences for definite articles in the object position by L2-TD, L1-SLI, and L1-TD children

\begin{tabular}{|c|c|c|c|c|c|c|c|}
\hline \multirow[b]{2}{*}{ Group } & \multicolumn{2}{|c|}{$\begin{array}{l}\text { Segment } 2 \\
\text { (Precritical) }\end{array}$} & \multicolumn{2}{|c|}{$\begin{array}{c}\text { Segment } 3 \\
\text { (Critical) }\end{array}$} & \multicolumn{2}{|c|}{$\begin{array}{c}\text { Segment } 4 \\
\text { (Postcritical) }\end{array}$} & \multirow{2}{*}{$\begin{array}{c}\begin{array}{c}\text { Mean Differ. } \\
\text { (Critical Segment) }\end{array} \\
\text { Ungr. - Gram. }\end{array}$} \\
\hline & Gram. & Ungr. & Gram. & Ungr. & Gram. & Ungr. & \\
\hline L2-TD & $430(86)$ & 445 (105) & 455 (93) & 607 (99) & 375 (107) & $368(95)$ & 152 \\
\hline L1-SLI & 388 (177) & $410(227)$ & 340 (236) & 405 (191) & 324 (229) & $393(220)$ & 65 \\
\hline L1-TD & $281(118)$ & $286(142)$ & $271(157)$ & $370(155)$ & 254 (138) & $284(142)$ & 99 \\
\hline
\end{tabular}

Note: Mean differences are calculated by subtracting the mean reaction times on the grammatical condition from the mean reaction times on the ungrammatical condition. L2, second language; TD, typically developing; L1, first language; SLI, specific language impairment. 
Chondrogianni et al.: Production and processing in L2 and SLI children

$p<.001, \eta_{\mathrm{p}}^{2}=0.59$; and a significant interaction between Position and Group in the per participants analysis, $F_{1}(1,63)=4.74, p<.01, \eta_{\mathrm{p}}^{2}=0.13 ; F_{2}(1,21)=$ $2.88, p=0.078, \eta_{\mathrm{p}}^{2}=0.22$.

For the critical segment (Segment 3), we found a main effect of Grammaticality, $F_{1}(1,63)=50.55, p<.001, \eta_{\mathrm{p}}^{2}=0.45 ; F_{2}(1,21)=31.53, p<.001, \eta_{\mathrm{p}}^{2}=$ 0.6 , as the RTs in the ungrammatical condition were significantly longer than in the grammatical condition. There was also a main effect of Group, $F_{1}(1$, $63)=3.892, p<.05, \eta_{\mathrm{p}}^{2}=0.110 ; F_{2}(1,21)=15.35, p<.001, \eta_{\mathrm{p}}^{2}=0.59$. Consecutive pairwise comparisons using Bonferroni correction revealed that the L2-TD children had longer RTs than the L1-TD children in the per participant $(p<.05)$ and the per item analysis $(p<.05)$. The L1-SLI children had longer RTs than the L1-TD children in the per item $(p<.01)$ but not in the per participant analysis $(p>.1)$; there was no difference in speed between the L2-TD children and the L1-SLI children.

For the postcritical segment, there was a main effect of Position, $F_{1}(1,63)=$ $296.626, p<.001, \eta_{\mathrm{p}}^{2}=0.83 ; F_{2}(1,21)=291.6, p<.001, \eta_{\mathrm{p}}^{2}=0.93$, and a main effect of Group, $F_{1}(1,63)=5.55, p<.01, \eta_{\mathrm{p}}^{2}=0.15 ; F_{2}(1,21)=14.69, p<$ $.001, \eta_{\mathrm{p}}^{2}=0.58$. Consecutive post hoc comparisons using Bonferroni correction revealed that the L2-TD children had significantly longer RTs than the L1-TD children in the per participant $(p<.01)$ and the per item $(p<.001)$ analysis, but their RTs did not differ from the L1-SLI children. The L1-SLI children had longer RTs than the L1-TD children in the per item analysis $(p<.01)$ and there was a tendency in the per participant analysis $(p=.071)$.

Clitic pronouns. The residual RTs for direct object clitic pronouns are presented in Table 4. To examine whether L1-TD, L2-TD, and L1-SLI children were sensitive to the grammatical violations due to clitic omission, we ran a repeated-measures ANOVA with Grammaticality (grammatical, ungrammatical) as the within-subjects factors and Group (L2-TD, L1-SLI, L1-TD) as the betweensubjects factor in a per participants $\left(F_{1}\right)$ and a per items $\left(F_{2}\right)$ analysis for each segment separately.

For the precritical segment (Segment 4), we found a main effect of Grammaticality in the per participant analysis, $F_{1}(1,63)=3.86, p=.054, \eta_{\mathrm{p}}^{2}=0.06 ; F_{2}(1$, $27)=3.86, p>.1, \eta_{\mathrm{p}}^{2}=0.06$, but in the opposite direction from the one predicted for the critical segment: RTs to the grammatical condition were longer than to the ungrammatical condition. There was also a main effect of Group, $F_{1}(1,63)$ $=5.12, p<.01, \eta_{\mathrm{p}}^{2}=0.14 ; F_{2}(1,27)=3.23, p=.055, \eta_{\mathrm{p}}^{2}=0.19$. Post hoc comparisons using Bonferroni correction revealed that the L2-TD children $(p<$ $.01)$ and the children with SLI $(p=.05)$ had longer RTs than the L1-TD children, but there was no difference in speed between the L2-TD and the L1-SLI children.

For the critical segment (Segment 5), we found a main effect of Group in the per item analysis, $F_{1}(1,63)=1.98, p>.1, \eta_{\mathrm{p}}^{2}=0.057 ; F_{2}(1,21)=291.60, p<$ $.05, \eta_{\mathrm{p}}^{2}=0.93$, and a significant interaction between Grammaticality and Group in the per participant analysis, $F_{1}(1,63)=3.18, p<.05, \eta_{\mathrm{p}}^{2}=.09 ; F_{2}(1,21)=$ $1.18, p>.3, \eta_{\mathrm{p}}^{2}=0.08$. To unpack the interaction, we ran paired-samples $t$ tests 
Table 4. Mean (standard deviation) residual reaction times and mean differences (critical segment) for the grammatical and ungrammatical sentences for clitic pronouns by L2-TD, L1-SLI, and L1-TD children

\begin{tabular}{|c|c|c|c|c|c|c|c|}
\hline \multirow[b]{2}{*}{ Group } & \multicolumn{2}{|c|}{$\begin{array}{l}\text { Segment } 4 \\
\text { (Precritical) }\end{array}$} & \multicolumn{2}{|c|}{$\begin{array}{l}\text { Segment } 5 \\
\text { (Critical) }\end{array}$} & \multicolumn{2}{|c|}{$\begin{array}{c}\text { Segment } 6 \\
\text { (Postcritical) }\end{array}$} & \multirow{2}{*}{$\begin{array}{c}\begin{array}{c}\text { Mean Differ. } \\
\text { (Critical Segment) }\end{array} \\
\text { Ungr. - Gram. }\end{array}$} \\
\hline & Gram. & Ungr. & Gram. & Ungr. & Gram. & Ungr. & \\
\hline L2-TD & $504(221)$ & $482(200)$ & $464(265)$ & $509(301)$ & 333 (180) & $313(174)$ & 45 \\
\hline L1-SLI & $472(221)$ & 444 (193) & $480(261)$ & 428 (221) & $355(212)$ & $305(180)$ & -52 \\
\hline L1-TD & 395 (117) & 357 (129) & $356(149)$ & 417 (157) & 235 (116) & $223(124)$ & 61 \\
\hline
\end{tabular}

Note: Mean differences are calculated by subtracting the mean reaction times on the grammatical condition from the mean reaction times on the ungrammatical condition. A negative mean difference represents that the mean for the ungrammatical condition is smaller than the mean for the grammatical condition. L2, second language; TD, typically developing; L1, first language; SLI, specific language impairment. 
for each group separately. The L1-TD group had longer RTs in the ungrammatical compared to the grammatical condition, $t(29)=-2.49, p<.05, d=0.39$. The L2TD group had also longer RTs in the ungrammatical compared to the grammatical condition (grammatical $=464 \mathrm{~ms}$, ungrammatical $=509 \mathrm{~ms}), t(19)=-2.51$, $p<.05$, and there was a small effect size $(d=0.16)$. Given that the precritical segment showed the opposite effect (longer RTs in the grammatical compared to the ungrammatical condition), the Grammaticality effect in the critical segment cannot be attributed to the effect found in the precritical segment. The L1-SLI group did not show a significant difference between the ungrammatical and the grammatical condition (Table 4). There was only a numerical difference in the opposite direction (grammatical $=480 \mathrm{~ms}$, ungrammatical $=428 \mathrm{~ms}$ ), as indicated by the negative mean difference $(-52)$ and a negative effect size $(d=-0.22)$. The different pattern in the children with SLI gave rise to the Grammaticality $\times$ Group interaction.

For the postcritical segment (Segment 6), there was a main effect of Grammaticality in the per participants analysis, $F_{1}(1,63)=5.52, p<.05, \eta_{\mathrm{p}}^{2}=0.08$; $F_{2}(1,27)=1.78, p>.1, \eta_{\mathrm{p}}^{2}=0.05$; RTs in the grammatical condition were longer than in the ungrammatical condition and indicates no spill-over effect from the critical segment. There was also a main effect of Group, $F_{1}(1,63)=4.76, p<$ $.05, \eta_{\mathrm{p}}^{2}=0.09 ; F_{2}(1,21)=3.23, p=.055, \eta_{\mathrm{p}}^{2}=0.19$. Post hoc comparisons using Bonferroni correction showed that the L2-TD children and the L1-SLI children had longer RTs than the L1-TD children ( $p<.05$ in both cases); there was no difference in speed between the L2-TD and the L1-SLI children.

\section{DISCUSSION}

This study investigated production and on-line comprehension of sentences involving definite articles and clitic pronouns in Greek-speaking TD-L2 children and monolingual children with SLI. The rationale for this comparison was to find out whether the similarities between the two populations attested in previous research using production tasks (e.g., Paradis, 2004) also hold for definite articles and clitic pronouns, as well as to trace the source of the problem in the two populations. L2-TD children acquire language in a typical manner and other factors, such as the amount of L2 input and the properties of the L1, can affect the acquisition of their L2 (Paradis, 2010). Conversely, children with SLI have been shown to have processing limitations and less efficient language learning systems (Montgomery $\&$ Leonard, 1998, 2006). These differences between the two populations may be masked in production due to their (low) vocabulary abilities, their lexical access problems (Windsor \& Kohnert, 2004), the degree of input and length of exposure to the L2 in the L2-TD children, or the amount of treatment received by the children with SLI, or a combination of these factors. Differences between the two groups may surface when sensitive experimental methods are employed.

To address the nature of the grammatical representations in the two populations, we used two elicitation tasks targeting production of definite articles and clitics and an on-line comprehension task. The on-line task investigated how L2-TD and L1-SLI children process grammatical violations with articles and clitic pronouns, 
while they were listening to sentences on-line for comprehension. The aim of this task was not to explore reference assignment of articles and pronouns but to find out whether L2-TD children and children with SLI were sensitive to the omission of these morphemes in real-time. The combination of these tasks can help us understand the relationship between performance on production and sensitivity to grammatical violations.

\section{Production of definite articles and clitics in L2-TD children and children with SLI}

The first research question examined whether L2-TD children and children with SLI differ in terms of accuracy and error patterns in the production of definite articles in different syntactic contexts (subject, object) and in the production of clitic pronouns.

The results from the production task revealed that the L2-TD children in the present study had significantly lower accuracy than the younger language-matched children with SLI and behaved similarly to the L2-TD children from the same population with similar age of onset and length of exposure reported in previous studies (Chondrogianni, 2008a, 2008b). The differences between the L2-TD children and the L1-SLI children emerged both in terms of accuracy and in terms of error types. The L2-TD children had significantly more omissions than the children with SLI, who had equal amount of omission and substitution errors for both definite articles and clitic pronouns. The L2-TD children and the children with SLI also produced overall significantly fewer D-elements (both definite articles and clitic pronouns) on both production tasks compared with the L1-TD children. The children with SLI had overall lower accuracy in the production of definite articles than the L1TD children, but the difference did not approach significance, probably due to the large range and substantial individual variability. Large individual variability was also observed in the case of the production of definite articles in the subject and the object position.

Finally, the three groups did not exhibit the previously reported asymmetry between the two elements; namely, they did not have higher production of definite articles compared with clitic pronouns (Chondrogianni, 2008a, 2008b; Smith, 2008). For the L2-TD children, this may have been due to the overall low accuracy on both articles and clitic pronouns.

For the L2-TD children, the results from the production task seem to suggest that L2-TD children of this particular age and with a length of exposure of fewer than 3 years have not yet reassembled the L1 features into the L2 morphophonological exponents; as a result, the rates of article and clitic pronoun omission are high. However, the production results alone cannot inform us as to whether there is a representational deficit due to feature interpretability (Tsimpli \& Mastropavlou, 2008). Omission rates cannot provide evidence for case misanalysis, and they cannot provide evidence that errors arise purely at spell-out nor that L2-TD children have reassembled the $\mathrm{L} 1$ features following $\mathrm{L} 2$ specifications at a representational level (Haznedar \& Schwartz, 1997; Lardiere, 2009).

In contrast, school-aged children with SLI seem to have overcome severe problems with definite articles and clitic pronouns reported in preschool children (e.g., 
Chondrogianni et al.: Production and processing in L2 and SLI children

Tsimpli \& Stavrakaki, 1999), as evidenced by their almost targetlike performance. This is in line with previous studies with school-aged children with SLI that report convergence to the target grammar at an older age after receiving sufficient input or remediation (Stavrakaki, 2001; Tsimpli \& Mastropavlou, 2008). The findings from the children with SLI of the present study contrast with the results on clitic pronouns from older children with SLI from Stavrakaki and van der Lely (2011), who reported variable production for clitic pronouns (65\% at the group level). The production data from the children with SLI seem to suggest that representational problems due to feature interpretability (Tsimpli \& Mastropavlou, 2008) or syntactic computations (Stavrakaki \& van der Lely, 2010) have been resolved at this age.

\section{Production-processing (a)symmetries in L2-TD children and children with SLI}

The second research question addressed the issue of whether L2-TD children and children with SLI would differ on the on-line task. On-line tasks may unravel similarities and differences between L2-TD children and children with SLI and help us understand the relationship between production and underlying representations. The rationale is that sensitivity to the grammatical violations induced by article and clitic omission in an on-line task indicates that the syntactic representations of children are intact. Previous studies have shown that Turkish-English L2-TD children were sensitive to the omission of tense morphemes in English despite variable production (Chondrogianni \& Marinis, 2012). Turkish-Dutch children were also sensitive to the omission of articles (Vasić \& Blom, 2011) and to gender mismatches in Dutch (Blom \& Vasić, 2011). In contrast, studies of children with SLI have shown that they are not sensitive to the grammatical violations induced by omission of tense morphemes in an on-line task (Leonard et al., 2009; Montgomery \& Leonard, 1998, 2006).

Our results revealed that the TD-L1 and L2-TD children exhibited longer RTs in sentences where the definite article and the clitic pronoun were omitted compared with sentences with definite articles and clitic pronouns. These results indicated that both TD populations were sensitive to the grammatical violations induced by the omission of the two D-elements. This was evidenced in the L2-TD children, even though they had low production of definite articles and clitics and although they had overall longer latencies than their monolingual peers. This suggests that the L2-TD children are able to process the grammatical violations due to definite article and clitic drop, even though they omit definite articles and clitics in their production.

It is crucial that the children with SLI exhibited sensitivity to definite article omission but not in sentences with clitic omission. In the definite article condition, they had longer RTs when the definite article was omitted compared with sentences with the definite article. In the clitic condition, however, they did not show a significant difference between the grammatical and the ungrammatical conditions and the difference between the grammatical and ungrammatical sentences followed the opposite than expected direction. These results suggest that children with SLI are able to process the grammatical violations due to definite article drop and that 
they also have high rates of article production. However, they cannot process the grammatical violation due to clitic drop, even though they produce it to a rate similar to that of their TD monolingual peers.

These findings have important implications regarding the relationship between production and abstract grammatical representations in L2-TD children and children with SLI, and they point toward different linguistic processes and profiles in the two populations. More specifically, a recurring debate in the L2 acquisition literature concerns the nature of L2 learners' abstract grammatical representations. Most studies with L2-TD children have provided evidence for an asymmetry between production and comprehension and have argued for the presence of abstract grammatical representations in L2-TD children despite variable production (Ionin \& Wexler, 2002; Paradis et al., 2008; Vasić \& Blom, 2011). The findings from the L2-TD children in our study are in line with those previously reported in literature using similar methodology (e.g., Chondrogianni \& Marinis, 2012). This is despite the fact that the L2-TD children in our study had fewer than 3 years of exposure and low production of definite articles and clitics. Therefore, although the production results considered in isolation would have pointed toward a representational deficit, possibly due to the (un)interpretability of the L2 features (Tsimpli \& Mastropavlou, 2008), the results from the on-line comprehension task argue for the MSIH (Haznedar \& Schwartz, 1997) and show that the L2-TD children have reassembled the $\mathrm{L} 1$ features into $\mathrm{L} 2$ categories at an abstract representational level.

The results from the children with SLI give rise to a more challenging picture, as this group did not exhibit a delayed or divergent profile for definite articles and clitics in production compared with the L1-TD children. However, in the on-line comprehension task, the children with SLI were not sensitive to the grammatical violations related to clitic drop. How can this asymmetry that follows the opposite than expected pattern between production and comprehension in the SLI population be explained?

According to the predictions of the IH (Tsimpli \& Mastropavlou, 2008), definite articles and clitics will remain inaccessible for Greek children with SLI because of the uninterpretable features carried by these morphemes. This account assumes that convergence to the target grammar will be achieved via a process of learning rather than an acquisition process, similarly with the assumptions of the implicit rule deficit account (Paradis \& Gopnik, 1997). For this reason, school-aged children who are older and have received more treatment may perform well on these structures because of learning rather than automatization of rule application (Paradis \& Gopnik, 1997; Ullman \& Gopnik, 1999). Within this rationale, rule learning may be more easily achievable in the case of definite articles than clitics. Definite articles consistently precede all noun types in Greek and are necessary for argument assignment. Conversely, clitics are dependent on discourse factors and do not consistently appear with a verbal host. ${ }^{6}$ According to SLTs in Greece, both of these structures are routinely treated in SLT practice using production tasks similar to the ones we used in this study. The children we tested had already been receiving between 1 and 3 years of treatment. It is possible that the children with SLI were able to successfully carry out the production task because of the application of well-trained strategies for both articles and clitic pronouns. 
Chondrogianni et al.: Production and processing in L2 and SLI children

Moreover, the strength of the association and co-occurrence between articles and nouns may have reached a sufficient threshold for rules to be internalized and to be applied implicitly in the on-line comprehension task (Leonard et al., 1997; Paradis \& Gopnik, 1997). For clitics, training may have led to almost targetlike production but has not given rise to abstract representations, as manifested in the on-line comprehension task, which taps more into implicit knowledge, rather than application of strategies.

The on-line results of the children with SLI seem to be accommodated within the CGCH (Stavrakaki \& van der Lely, 2010) that argues for intact performance on definite articles and impaired performance on clitic pronouns due to differences in derivational complexity. However, this account cannot predict the high performance on clitics in the production task by children with SLI. As mentioned previously, it is not clear why this account assumes that representational impairment will lead to optionality.

\section{Definite articles versus clitic pronouns}

The third research question concerned whether performance on definite articles and clitic pronouns would differ within all groups of children, as it had been previously reported (Chondrogianni, 2008; Marinis, 2003; Smith, 2008; Tsimpli $\&$ Stavrakaki, 2008). In the present study, we did not find an asymmetry between the two D-elements in production; numerical trends did not reach significance due to individual variability. We also did not find an asymmetry between the two Delements in the on-line comprehension task in the L1-TD and the L2-TD children, because both groups were sensitive to the grammatical violations induced by article and clitic omission. However, the children with SLI showed a dissociation between the two D-elements, because they exhibited a grammaticality effect in the case of articles but not in the case of clitics.

How can the dissociation between definite articles and clitic pronouns in the children with SLI be explained? In the sentences with clitics, children have to access the argument structure of the verb and keep track of the various referents engaged in a particular action. When the children show sensitivity to clitic drop, this indicates that they can process the syntactic and discourse properties associated with the clitic plus verb complex, and they can detect that the verbal argument is missing in these contexts. For the children with SLI, the lack of sensitivity to clitic drop in the on-line comprehension task may reflect the argument status of the clitic and that children with SLI fail to process a derivationally more complex argument that appears in a noncanonical position. To disentangle the nature of the difficulties with clitics in children with SLI, that is, whether they are discourse or movement related, future research would need to compare the on-line comprehension of clitics to other pronominal elements in Greeks, such as strong pronouns, which are referential and derivationally not complex; that is, they do not involve movement. Furthermore, to address potential difficulties with (head) movement, future research could investigate other structures involving head movement in Greek, such as adverbial placement. (See Alexiadou \& Stavrakaki, 2006, for problems with head movement in Greek-speaking aphasics.) 
Finally, although the surface account is not incompatible with the assumptions regarding the derivational properties of articles and clitics, in its core form, this account makes predictions based on the phonetic substance of these morphemes rather than on the derivational complexity of the two D-elements. Therefore, the surface account (Leonard et al., 1997) alone cannot explain the asymmetry found in the on-line comprehension task between definite articles and clitic pronouns in the children with SLI; although both D-elements have the same phonetic salience, the children with SLI were sensitive only to article drop and not to clitic drop.

\section{CONCLUSION}

The present study compared production and on-line processing of articles and clitic pronouns in school-aged Greek-speaking L2-TD children and children with SLI. The two populations showed distinct profiles in both production and on-line comprehension. L2-TD children had low accuracy on both D-elements. However, they were sensitive to the grammatical violations induced by definite article and clitic omission in the on-line comprehension task. This was despite their overall low language abilities and their longer latencies compared with their L1-TD peers. By contrast, children with SLI were only sensitive to definite article drop, but not to clitic drop, in the on-line comprehension task even though they had high production of clitics and articles. For the L2-TD children, these results suggest output problems related to production but not lack of grammatical representations (Haznedar \& Schwartz, 1997). For the children with SLI, derivationally complex structures, like clitics, can be successfully remediated and can show a high rate of production. However, results from more sensitive implicit tasks indicate that despite high rates of production, children with SLI have difficulties internalizing derivationally complex structures like clitics. These results also suggest that online comprehension tasks may help us differentiate between the language profiles of the L2-TD children and the children with SLI.

\section{NOTES}

1. Note that chance level performance on the comprehension task is $25 \%$ because it is a four-picture selection task. Therefore, the performance on the comprehension task is above chance level.

2. Tsimpli and Mastropavlou (2008) did not control for proficiency and length of exposure in the L2 children, and these factors have been shown to not necessarily correlate with age in this population (Chondrogianni, 2008a).

3. The children who produced clitics in the narrative task were a subset of the children who produced clitics in the elicited production task, hence the difference in terms of accuracy. More specifically, the L2 children who produced clitics in the narrative task were the ones who had the felicitous "clitic-contexts" in their discourse structure (Chondrogianni, 2008a).

4. It should be noted that Tsimpli and her colleagues examined articles and clitics in referential contexts and not in expletive, nonreferential contexts. It is thus questionable why it is assumed that articles and clitic pronouns in a referential context will not be acquired by child L2 learners. 
Chondrogianni et al.: Production and processing in L2 and SLI children

5. Accusative case marking and its interaction with the definiteness of the noun are acquired in L1-TD Turkish-speaking children before the age of 4 years (e.g., see Ketrez, 2005). Semantic distinctions related to indefiniteness and scope ambiguities are acquired at a later age (around the age of 7). In the present study, we examined the use of simple noun phrases in definite contexts and thus expect the L2-TD children in our study to have the relevant L1 (semantic and syntactic) properties in place.

6. These assumptions about the properties of articles and clitics related to consistency are not inherent to the IH or the IRD accounts. These assumptions can be also accommodated by the surface account relating to the formation of paradigms and by the feature reassembly account on the nature of the $\mathrm{L} 2$ morphophonological exponents.

\section{REFERENCES}

Alexiadou, A., \& Stavrakaki, S. (2006). Clause structure and verb movement in a Greek English speaking bilingual patient with Broca's aphasia: Evidence from adverb placement, Brain \& Language, 96, 207-220.

Anagnostopoulou, E. (1999). Conditions on clitic doubling. In R. H. van Riemsdijk (Ed.), Clitics in the languages of Europe (Vol. 3, pp. 759-798). Berlin: Mouton de Gruyter.

Anagnostopoulou, E. (2003). The syntax of ditransitives: Evidence from clitics. Berlin: Mouton de Gruyter.

Arvaniti, A. (1991). The phonetics of Greek rhythm and its phonological implications. $\mathrm{PhD}$ dissertation, University of Cambridge.

Bialystok, E., Craik, F. I. M., \& Luk, G. (2008). Lexical access in bilinguals: Effects of vocabulary size and executive control. Journal of Neurolinguistics, 21, 522-538.

Bishop, D. V. M., Carlyon, R. P., Deeks, J. M., \& Bishop, S. J. (1999). Auditory temporal processing impairment: Neither necessary nor sufficient for causing language impairment in children. Journal of Speech, Language, and Hearing Research, 42, 1295-1310.

Blom, E., \& Vasić, N. (2011). The production and processing of determiner-noun agreement in child L2 Dutch. Linguistic Approaches to Bilingualism, 1, 265-290.

Bošković, Ž. (2008). What will you have, DP or NP? Proceedings of NELS, 37, 101-114.

Bottari, P., Cipriani, P., Chilosi, A. M., \& Pfanner, L. (1998). The determiner system in a group of Italian children with SLI. Language Acquisition, 7, 285-315.

Chomsky, N. (1995). The minimalist program, Cambridge, MA: MIT Press.

Chondrogianni, V. (2008a). The acquisition of determiners and clitic pronouns by child and adult L2 learners of Greek. Unpublished doctoral dissertation, University of Cambridge.

Chondrogianni, V. (2008b). Comparing child and adult L2 acquisition of the Greek DP: Effects of age and construction. In B. Haznedar \& E. Gavruseva (Eds.), Current trends in child L2 acquisition: Generative approaches (pp. 97-142). Amsterdam: John Benjamins.

Chondrogianni, V., \& Marinis, T. (2012). Production and processing asymmetries in the acquisition of tense morphology by sequential bilingual children. Bilingualism: Language and Cognition, $12,1-19$.

Clahsen, H. (2008). Behavioral methods for investigating morphological and syntactic processing in children. In I. A. Sekerina, E. M. Fernández, \& H. Clahsen (Eds.), Developmental psycholinguistics: On-line methods in children's language processing (pp. 1-27). Amsterdam: John Benjamins.

Cohen, J. (1992). A power primer. Psychological Bulletin, 112, 155-159.

Diamanti, M. (2000). Aples morphosyntaktikes domes sto logo pediou me eidiki glwssiki diataraxi. Paper presented at the 8th Symposium of the Panhellenic Association of Logopedists, Athens.

Enç, M. (1991). The semantics of specificity. Linguistic Inquiry, 22, 1-25.

Genesee, F., Paradis, J., \& Crago, M. (2005). Domain-general versus domain-specific accounts of specific language impairment: Evidence from bilingual children's acquisition of object pronouns. Language Acquisition, 13, 33-62.

Goad, H., \& White, L. (2006). Ultimate attainment in interlanguage grammars: A prosodic approach. Second Language Research, 22, 243-268. 
Chondrogianni et al.: Production and processing in L2 and SLI children

Grüter, T. (2005). Comprehension and production of French object clitics by child second language learners and children with specific language impairment. Applied Psycholinguistics, 26, 363391.

Grüter, T., \& Crago, M. (2012). Object clitics and their omission in child L2 French: The contributions of processing limitations and L1 transfer. Bilingualism: Language and Cognition, 15, 531549.

Håkansson, G., \& Nettelbladt, U. (1996). Similarities between SLI and L2 children: Evidence from the acquisition of Swedish word order. In C. E. Johnson \& J. H. V. Gilbert (Eds.), Children's language (pp. 135-151). Mahwah, NJ: Erlbaum.

Haznedar, B., \& Schwartz, B. D. (1997). Are there optional infinitives in child L2 acquisition? In E. Hughes, M. Hughes, \& A. Greenhill (Eds.), Proceedings of the 21st Boston University Conference on Language Development (pp. 257-268). Somerville, MA: Cascadilla Press.

Institute for Language and Speech Processing. (2001). Basic vocabulary. Athens: Author. Retrieved from http://www.ilsp.gr/ippotis/greeklang.html

Ionin, T., \& Wexler, K. (2002). Why is "is" easier than "-s"? Acquisition of tense/agreement morphology by child second language learners of English. Second Language Research, 18, 95-136.

Jakubowicz, C., Nash, L., Rigaut, C., \& Gerard, C.-L. (1998). Determiners and clitic pronouns in French-speaking children with SLI. Language Acquisition, 7, 113-160.

Ketrez, N. (2005). Children's scope of indefinite objects. Unpublished doctoral dissertation, University of California, Los Angeles.

Kornfilt, J. (1997). Turkish. London: Routledge.

Kowaluk, A. (2001). The development of pronouns and determiners in the second language: A study of Polish learners of English. Unpublished doctoral dissertation, University of Cambridge.

Lardiere, D. (2005). On morphological competence. In L. Dekydtspotter, R. A. Sprouse, \& A. Liljestrand (Eds.), Proceedings of the 7th Generative Approaches to Second Language Acquisition Conference (pp. 178-192). Somerville, MA: Cascadilla Press.

Lardiere, D. (2009). Some thoughts on the contrastive analysis of features in second language acquisition. Second Language Research, 25, 173-227.

Leonard, L. B. (1989). Language learnability and specific language impairment in children. Applied Psycholinguistics, 10, 179-202.

Leonard, L. B. (2009). Cross-linguistic studies of child language disorders. In R. Schwartz (Ed.), Handbook of child language disorders (pp. 308-324). New York: Psychology Press.

Leonard, L. B., Eyer, J. A., Bedore, L. M., \& Grela, B. G. (1997). Three accounts of the grammatical morpheme difficulties of English-speaking children with specific language impairment. Journal of Speech, Language, and Hearing Research, 40, 741-753.

Leonard, L. B., Miller, C., \& Finneran, D. (2009). Grammatical morpheme effects on sentence processing by school-aged adolescents with specific language impairment. Language and Cognitive Processes, 24, 450-478.

Longobardi, G. (1994). Reference and proper names: A theory of N-movement in syntax and logical form. Linguistic Inquiry, 25, 609-665.

Manika, S., Varlokosta, S., \& Wexler, K. (2011). The lack of omission of clitics in Greek children with SLI: An experimental study. In N. Danis, K. Mesh, \& H. Sung (Eds.), Proceedings of the 35th Boston University Conference on Language Development (pp. 429-437). Somerville, MA: Cascadilla Press,

Marinis, T. (2000). The acquisition of clitic objects in Modern Greek: Single clitics, clitic doubling, clitic left dislocation. In A. Alexiadou, N. Fuhrop, U. Kleinhenz, \& P. Law (Eds.), ZAS working papers 15 (pp. 260-283). Berlin: Humboldt University.

Marinis, T. (2003). The acquisition of DP in Modern Greek. Amsterdam: John Benjamins.

Marinis, T. (2008). Syntactic processing in developmental and acquired language disorders. In M. J. Ball, M. Perkins, N. Mueller, \& S. Howard (Eds.), The handbook of clinical linguistics (pp. 198-211). Oxford: Blackwell.

Marinis, T. (2010). Using on-line processing methods in language acquisition research. In E. Blom \& S. Unsworth (Eds.), Experimental methods in language acquisition research (pp. 139-162). Amsterdam: John Benjamins.

Marinis, T., \& Chondrogianni, V. (2011). Comprehension of reflexives and pronouns in sequential bilingual children: Do they pattern similarly to L1 children, L2 adults, or children with specific language impairment? Journal of Neurolinguistics, 24, 202-212. 
Chondrogianni et al.: Production and processing in L2 and SLI children

Marinis, T., \& Saddy, D. (2013). Parsing the passive: Comparing children with Specific Language Impairment to sequential bilingual children. Language Acquisition 20, 155-179.

Marinis, T., \& van der Lely, H. (2007). Processing of $w h$-questions in children with G-SLI and typically developing children. International Journal of Language and Communication Disorders, 42, 557-582.

Mavrogiorgos, M. (2010). Clitics in Greek. A minimalist account of proclisis and enclisis. Amsterdam: John Benjamins.

Mastropavlou, M. (2006). The effect of phonological saliency and LF-interpretability in the grammar of Greek normally developing and language impaired children. Unpublished doctoral dissertation, Aristotle University of Thessaloniki.

Meisel, J. (2008). Child second language acquisition or successive first language acquisition? In B. Haznedar \& E. Gavruseva (Eds.), Current trends in child second language acquisition (pp. 5580). Amsterdam: John Benjamins.

Montgomery, J. W., \& Leonard, L. B. (1998). Real-time inflectional processing by children with specific language impairment: Effects of phonetic substance. Journal of Speech, Language, and Hearing Research, 41, 1432-1443.

Montgomery, J. W., \& Leonard, L. B. (2006). Effects of acoustic manipulation on the real-time inflectional processing of children with specific language impairment. Journal of Speech, Language, and Hearing Research, 49, 1238-1256.

Öztürk, B. (2005). Case, referentiality and phrase structure in Turkish. Amsterdam: John Benjamins.

Paradis, J. (2004). The relevance of specific language impairment in understanding the role of transfer in second language acquisition. Applied Psycholinguistics, 25, 67-76.

Paradis, J. (2005). Grammatical morphology in children learning English as a second language: Implications of similarities with specific language impairment. Language, Speech, and Hearing Services in the Schools, 36, 172-187.

Paradis, J. (2010a). Bilingual children's acquisition of English verb morphology: Effects of language dominance, structure difficulty, and task type. Language Learning, 60, 651-680.

Paradis, J. (2010b). The interface between bilingual development and specific language impairment. Applied Psycholinguistics, 31, 227.

Paradis, J., \& Crago, M. (2000). Tense and temporality: A comparison between children learning a second language and children with SLI. Journal of Speech, Language, and Hearing Research, $43,834-847$.

Paradis, J., Rice, M. L., Crago, M., \& Marquis, J. (2008). The acquisition of tense in English: Distinguishing child second language from first language and specific language impairment. Applied Psycholinguistics, 29, 689-722.

Paradis, M., \& Gopnik, M. (1997). Compensatory strategies in genetic dysphasia: Declarative memory. Journal of Neurolinguistics, 10, 173-185.

Prévost, P., \& White, L. (2000). Missing surface inflection or impairment in second language acquisition? Evidence from tense and agreement. Second Language Research, 16, 103-133.

Raven, J. C. (1998). The Coloured Progressive Matrices. Oxford: Oxford Psychologists Press.

Schaeffer, J. (2000). The acquisition of direct object scrambling and clitic placement: Syntax and pragmatics. Amsterdam: John Benjamins.

Schneider, W., Eschmann, A., \& Zuccolotto, A. (2002). E-Prime user's guide. Pittsburgh, PA: Psychology Software Tools.

Schwartz, B. D. (2003). Child L2 acquisition: Paving the way. In B. Beachley, A. Brown, \& F. Conlin (Eds.), Proceedings of the 27th Boston University Conference on Language Development (pp. 26-50). Somerville, MA: Cascadilla Press.

Segalowitz, N., \& Hulstijn, J. (2005). Automaticity in bilingualism and second language learning. In J. Kroll \& A. M. B. de Groot (Eds.), Handbook of bilingualism. psycholinguistic approaches (pp. 371-388). Oxford: Oxford University Press.

Seymour, H., Roeper, T., de Villiers, J., \& de Villiers, P. (2005). Diagnostic Evaluation of Language Variation (DELV $\left.{ }^{\mathrm{TM}}\right)$ : Norm-referenced. San Antonio, TX: Harcourt Assessment.

Sioupi, A. (2002). On the semantic nature of bare NP's in Greek. Paper presented at the 5th International Conference on Greek Linguistics, Sorbonne, Paris.

Smith, N. (2008). Morphosyntactic and phonological short-term memory skills of Greek pre-school children with specific language impairment. Unpublished doctoral dissertation, University of Reading. 
Chondrogianni et al.: Production and processing in L2 and SLI children

Snedeker, J. (2009). Children's sentence processing. In E. Bavin (Ed.), The handbook of child language (pp. 331-338). Cambridge: Cambridge University Press.

Stavrakaki, S. (2001). SLI in Greek: aspects of syntactic production and comprehension. Unpublished PhD dissertation, Aristotle University of Thessaloniki.

Stavrakaki, S., \& Tsimpli, I. (2000). Diagnostic verbal IQ test for Greek preschool and school age children: Standardization, statistical analysis, psychometric properties. Paper presented at the 8th Symposium of the Panhellenic Association of Logopedists, Athens, Greece.

Stavrakaki, S., \& van der Lely, H. K. J. (2010). Production and comprehension of pronouns by Greek children with specific language impairment. British Journal of Developmental Psychology, 28, 189-216.

Trueswell, J. C., Sekerina, I. A., Hill, N., \& Logrip, M. (1999). The kindergarten path effect: Studying on-line sentence processing in young children. Cognition, 73, 89-134.

Tsakali, V., \& Wexler, K. (2003). Why do children omit clitics in some languages but not in others? In J. v. Kampen \& S. Baauw (Eds.), Proceedings of the Generative Approaches to Language Acquisition Conference, 2003 (pp. 493-504). Utrecht: LOT Publications.

Tsimpli, I. M. (2001). LF-interpretability and language development: A study of verbal and nominal features in normally developing and SLI Greek children. Brain and Language, 77, 432-448.

Tsimpli, I. M. (2003). Clitics and articles in L2 Greek. In J. M. Liceras, H. Zobl, \& H. Goodluck (Eds.), Proceedings of the 6th Generative Approaches to Second Language Acquisition Conference (pp. 331-339). Somerville, MA: Cascadilla Proceedings Project.

Tsimpli, I. M. (2005). Peripheral positions in early Greek. In M. Stavrou \& A. Terzi (Eds.), Advances in Greek generative syntax (pp. 179-216). Amsterdam: John Benjamins.

Tsimpli, I. M., \& Mastropavlou, M. (2008). Feature interpretability in L2 acquisition and SLI: Greek clitics and determiners. In H. Goodluck, J. Liceras, \& H. Zobl (Eds.), The role offormal features in second language acquisition (pp. 143-183). London: Routledge.

Tsimpli, I. M., \& Papadopoulou, D. (2006). Aspect and argument realization: A study on antecedentless null objects in Greek. Lingua, 116, 1595-1615.

Tsimpli, I. M., \& Stavrakaki, S. (1999). The effects of a morphosyntactic deficit in the determiner system: The case of a Greek SLI child. Lingua, 108, 31-85.

Ullman, M. T., \& Gopnik, M. (1999). Inflectional morphology in a family with inherited specific language impairment. Applied Psycholinguistics, 20, 51-117.

Van der Lely, H. K. J., \& Battell, J. (2003). Wh-movement in children with grammatical SLI: A test of the RDDR hypothesis. Language, 79, 153-181.

VanPatten, B., Keathing, G., \& Leeser, M. (2012). Missing verbal inflections as a representational problem. Linguistic Approaches to Bilingualism, 2, 109-140.

Varlokosta, S. (2002). Functional categories in Greek specific language impairment. In C. Clairis (Ed.), Recherches en linguistique grecque (pp. 303-306). Paris: L'Harmattan.

Vasić, N., \& Blom, E. (2011). Production and processing of determiners in Turkish-Dutch child L2 learners. In N. Danis, K. Mesh, \& H. Sung (Eds.), Proceedings of the 35th Boston University Conference on Language Development (pp. 616-627). Somervillle, MA: Cascadilla Press.

Vasić, N., Chondrogianni, V., Marinis, T., \& Blom, E. (2012). Processing of gender in TurkishDutch and Turkish-Greek L2 children. In A. K. Biller, E. Y. Chung, \& A. E. Kimball (Eds.), Proceedings of the 36th Boston University Conference on Language Development (pp. 646659). Somerville, MA: Cascadilla Press.

Windsor, J., \& Kohnert, K. (2004). The search for common ground: Part I. lexical performance by linguistically diverse learners. Journal of Speech Language and Hearing Research, 47, 877890 .

Zdorenko, T., \& Paradis, J. (2011). Articles in child L2 English: When L1 and L2 acquisition meet at the interface. First Language, 21, 1-25. 